NBER WORKING PAPER SERIES

CLEARING UP THE FISCAL MULTIPLIER MORASS:

PRIOR AND POSTERIOR ANALYSIS

\author{
Eric M. Leeper \\ Nora Traum \\ Todd B. Walker \\ Working Paper 21433 \\ http://www.nber.org/papers/w21433 \\ NATIONAL BUREAU OF ECONOMIC RESEARCH \\ 1050 Massachusetts Avenue \\ Cambridge, MA 02138 \\ July 2015
}

We would like to thank seminar participants at the Bank of Canada, the 2011 Bundesbank Spring Conference, the Federal Reserve Bank of Dallas, the 2011 Konstanz Seminar on Monetary Theory and Policy, the 2011 SED annual meeting, and Henning Bohn, Marco Del Negro, Berthold Herrendorf, Campbell Leith, Giorgio Primiceri, Morten Ravn, Harald Uhlig, Tao Zha, Marty Eichenbaum, and anonymous referees for helpful comments. The views expressed herein are those of the authors and do not necessarily reflect the views of the National Bureau of Economic Research.

NBER working papers are circulated for discussion and comment purposes. They have not been peerreviewed or been subject to the review by the NBER Board of Directors that accompanies official NBER publications.

(C) 2015 by Eric M. Leeper, Nora Traum, and Todd B. Walker. All rights reserved. Short sections of text, not to exceed two paragraphs, may be quoted without explicit permission provided that full credit, including $(\odot$ notice, is given to the source. 
Clearing Up the Fiscal Multiplier Morass: Prior and Posterior Analysis

Eric M. Leeper, Nora Traum, and Todd B. Walker

NBER Working Paper No. 21433

July 2015

JEL No. C11,E62,E63

\begin{abstract}
$\underline{\text { ABSTRACT }}$
We use Bayesian prior and posterior analysis of a monetary DSGE model, extended to include fiscal details and two distinct monetary-fiscal policy regimes, to quantify government spending multipliers in U.S. data. The combination of model specification, observable data, and relatively diffuse priors for some parameters lands posterior estimates in regions of the parameter space that yield fresh perspectives on the transmission mechanisms that underlie government spending multipliers. Posterior mean estimates of short-run output multipliers are comparable across regimes-about 1.4 on impact-but much larger after 10 years under passive money/active fiscal than under active money/passive fiscal — means of 1.9 versus 0.7 in present value.
\end{abstract}

Eric M. Leeper

Department of Economics

Indiana University

105 Wylie Hall

Bloomington, IN 47405

and Center for Applied Economics and

$\square$ Policy Research

and also NBER

eleeper@indiana.edu

Nora Traum

Department of Economics

Nelson Hall Campus Box 8110

North Carolina State University

Raleigh, NC 27695

nora_traum@ncsu.edu
Todd B. Walker

Department of Economics

105 Wylie Hall

Indiana University

Bloomington, IN 47405

walkertb@indiana.edu

An online appendix is available at:

http://www.nber.org/data-appendix/w21433 


\title{
Clearing Up the Fiscal Multiplier Morass: PRIOR AND POSTERIOR ANALYSIS*
}

\author{
Eric M. Leeper ${ }^{\dagger} \quad$ Nora Traum ${ }^{\ddagger} \quad$ Todd B. Walker ${ }^{\S}$
}

\section{INTRODUCTION}

The global recession of 2008 and the resulting fiscal stimulus packages in many countries reignited academic interest in government spending multipliers to spawn a new and growing theoretical and empirical literature. Despite intense professional attention, no consensus has emerged on the dynamic impacts of government spending on macroeconomic aggregates. Because the fiscal multiplier is a complex object that depends on nearly every detail of private and policy behavior, different model specifications or identifying assumptions can produce wildly different quantitative predictions of multipliers. Two broad studies neatly illustrate what we call the fiscal multiplier morass: Coenen et al. (2012) examine seven dynamic stochastic general equilibrium (DSGE) models to report "a robust finding across all models that fiscal policy can have sizable output multipliers;" Cogan et al. (2010) study closely related models and similar data to conclude, "multipliers are less than one.... The impact in the first year is very small. And as the government purchases decline in the later years of the simulation, the multipliers turn negative." ${ }^{1}$ Starkly different conclusions from similar models and data constitute a morass.

This paper uses Bayesian prior and posterior analysis to clear up the morass by tracing differences in estimates of multipliers to different model specifications. We augment a monetary DSGE model from the class that Smets and Wouters (2005, 2007) and Christiano et al. (2005) develop with a rich set of fiscal details: government spending that may be valued as a public good, explicit rules for fiscal instruments, a maturity structure of government debt, and distorting steady-state taxes. We also go beyond existing empirical analyses of multipliers to consider alternative monetary-fiscal regimes: either active monetary policy coupled with passive fiscal policy (regime M) or active fiscal policy together with passive monetary policy (regime F) ${ }^{2}$

\footnotetext{
${ }^{*}$ We would like to thank seminar participants at the Bank of Canada, the 2011 Bundesbank Spring Conference, the Federal Reserve Bank of Dallas, the 2011 Konstanz Seminar on Monetary Theory and Policy, the 2011 SED annual meeting, and Henning Bohn, Marco Del Negro, Berthold Herrendorf, Campbell Leith, Giorgio Primiceri, Morten Ravn, Harald Uhlig, Tao Zha, Marty Eichenbaum, and anonymous referees for helpful comments.

${ }^{\dagger}$ Indiana University and NBER; eleeper@indiana.edu.

${ }^{\ddagger}$ North Carolina State University; nora_traum@ncsu.edu

${ }^{\S}$ Indiana University; walkertb@indiana.edu.

${ }^{1}$ Coenen et al. (2012) delves into some of the subtleties responsible for the differences in multipliers across studies. Gechert and Will (2012, p. 28) examine 89 multiplier studies spanning many methodologies to conclude that "reported multipliers very much depend on the setting and method chosen."

${ }^{2} \mathrm{An}$ active authority is defined as an authority who is not constrained by current budgetary conditions and freely
} 
Prior predictive analysis reports the probability distribution of multiplier values that a particular specification can produce before confronting data. That analysis finds, for example, that it is impossible for standard real business cycle models to produce large multipliers, while new Keynesian models with a substantial fraction of rule-of-thumb agents are quite unlikely to generate small multipliers, regardless of the information that data contain about multipliers.

Prior predictive analysis guides our choice of model to take to the data. We seek a specification that a priori is consistent with either small or large multipliers, depending on estimated parameter values. The prior analysis suggests that a model that permits government spending to complement or substitute for private consumption and conditions on either regime $\mathrm{M}$ or regime $\mathrm{F}$ supports the widest ranges for multipliers.

We maintain the agnostic spirit of the prior predictive analysis when we estimate by employing relatively diffuse prior distributions over some model parameters and by considering distinct priors that place the economy in one of the two monetary-fiscal regimes. The fiscal details in our model and the data set, both of which rarely appear in estimated DSGE models, permit the posterior to land in regions of the parameter space that produce 90-percent fresh perspectives on the transmission mechanisms that underlie government spending multipliers. Despite our diffuse a priori views about the sizes and the dynamics of multipliers, U.S. data are highly informative: they narrow the posterior range of multipliers substantially to help us clear up the multiplier morass.

Over the full sample period, 1955q1-2014q2, the posterior estimates deliver high degrees of nominal rigidities, strong habit formation and complementarity between government and private consumption in both policy regimes. These estimates produce comparable short-run output multipliers across regimes - mean impact multipliers are about 1.4-but substantially larger multipliers in regime $\mathrm{F}$ than in regime $\mathrm{M}$ at long horizons - after 10 years the mean present-value multiplier is 1.9 in F, but 0.7 in M. Consumption effects are positive in both regimes, with multipliers that hover around 0.2 to 0.3 in present value. Investment multipliers are decidedly negative in regime $\mathrm{M}$ but more likely to be positive in regime F: 90 -percent credible sets at 10 years are $[-1.4,-0.8]$ in $\mathrm{M}$ and $[-0.2,0.3]$ in $\mathrm{F}$.

Although private parameter estimates are quite similar across policy regimes, the two monetaryfiscal mixes imply different fiscal financing schemes that transmit government spending through the economy in different ways. Posterior estimates for the full sample yield somewhat unusual passive fiscal behavior in regime M: higher government debt raises future lump-sum transfers and the full brunt of debt stabilization is borne by government spending reversals of the kind that Corsetti et al. (2012) emphasize. In regime F stabilization occurs from revaluations of debt through surprise changes in inflation and bond prices. Steady-state distorting tax rates ensure that revenues endogenously respond to economic conditions in both regime, even though the constant tax rates cannot stabilize debt.

At the risk of some oversimplification, we can succinctly describe the transmission mechanisms.

chooses the decision rule it wants. A passive authority is constrained by the consumers' and firms' optimizations and by the actions of the active authority, so the passive authority must stabilize debt. See Leeper (1991), Sims (1994), Woodford (1995), and Cochrane (1999) for more discussion. 
Three aspects of behavior lie behind government spending impacts in regime M: strong rigiditiesprice and wage stickiness and habit formation - complementarity of government spending to private consumption, and fiscal financing through spending reversals. Complementarity ensures that higher spending initially raises consumption even though long-run real interest rates also rise. Anticipated cuts in future government spending, coupled with higher transfers, raise household wealth and temper long-run real rate increases to support consumers' strong desire to smooth consumption at a level above steady state for many years after the initial spending impulse. Because the output boost is short-lived, higher consumption in the long run comes out of reduced investment.

This estimated transmission mechanism differs from convention — as in, for example, Galí et al. (2007), Woodford (2011) or Corsetti et al. (2012) —along several dimensions. First, most studies do not permit government spending to interact directly with consumption through preferences. Second, high estimated nominal rigidities dampen inflationary and real-interest rate effects. Third, estimated fiscal financing produces positive, rather than the usual negative, wealth effects. These differences account for the persistently positive consumption multipliers.

Based on previous work on government spending multipliers when monetary policy is passive, it may be surprising that our reported multipliers are not several times larger in regime $\mathrm{F}$ than in M. ${ }^{3}$ Although very large fiscal effects are possible when our model resides in regime $\mathrm{F}$, the moderate impacts that the posterior estimates produce stem primarily from three factors: high nominal rigidities, the existence of a maturity structure for nominal government debt, and the presence of steady-state taxes on labor and capital income.

Higher government spending financed by nominal bond sales raises household wealth when fiscal policy is active and future surpluses are not expected to adjust to stabilize debt. Rigid prices convert higher nominal debt into sustained increases in real debt and in household wealth. Higher wealth boosts consumption demand, which price stickiness translates into higher labor demand, rather than higher goods prices. Because the real value of debt cannot fall significantly through a higher price level, it declines instead through lower bond prices; the maturity structure for bonds permits revaluation to occur through higher future inflation. With inflation rising only modestly, long-run real interest rates rise even under passive monetary policy, just as they do in regime $\mathrm{M}$ when monetary policy is active.

Long-run output multipliers are substantially larger in regime F because real wages and employment increase strongly and persistently to increase human wealth and sustain consumption demand. Consumption multipliers remain positive many years after the government spending increase has dissipated without crowding out investment, as occurs in regime M. Multipliers are not implausibly large in regime $\mathrm{F}$, as previous research may suggest, because steady-state taxes levied against factor incomes raise aggregate tax revenues along with the expansion in real economic activity to temper the wealth effects that active fiscal policy engenders. Steady-state tax rates capture the reality that even if a government does not systematically adjust tax schedules when government

\footnotetext{
${ }^{3}$ Work on government spending increases by Kim (2003), Christiano et al. (2011), Davig and Leeper (2011) and Dupor and $\mathrm{Li}$ (2015) finds that in regime $\mathrm{F}$ or at the zero lower bound for nominal interest rates, output multipliers can exceed 2 , real interest rates fall and inflation rises substantially.
} 
debt rises, revenues nonetheless rise with incomes because existing tax rates remain in place.

As in regime $\mathrm{M}$, the posterior estimates in regime $\mathrm{F}$ deliver a very different transmission mechanism for government spending than appears elsewhere in the literature. Sizeable multipliers for output and consumption arise despite higher long-run real interest rates. Dupor and Li (2015) argue that passive monetary policy gives government spending expansions unreasonably large inflationary consequences that are inconsistent with empirical evidence. This does not occur in our estimates because the model includes fiscal details that most analyses neglect.

The paper's emphasis on monetary-fiscal interactions is tightly connected to data. Previous work relies on theoretical or calibrated results to argue that government spending's impacts can be quite different across regimes $\mathrm{M}$ and $\mathrm{F}$. This paper confronts those theoretical possibilities with data to find that model fit can be comparable across regions of the parameter space that produce different government spending transmission mechanisms and multiplier dynamics.

\section{The Models}

The models we use for prior predictive analysis share several details with the class of models used to evaluate the size of fiscal multipliers: (1) forward-looking, optimizing agents; (2) households who receive utility from consumption and leisure and additionally may value government consumption; (3) a distinction between households who can save ("savers") and who are constrained to consume their income each period ("non-savers"); (4) production sectors that use capital and labor inputs; (5) monopolistic competition in the goods and labor sectors; (6) empirically relevant nominal and real frictions; (7) fiscal and monetary authorities who set their instruments using simple feedback rules; and (8) the economy at its cashless limit.

Our model structure nests many of the frameworks that researchers have used to quantify fiscal multipliers, but expands on those frameworks by filling in many details of the fiscal side of the model. Those details include allowing for public goods that may be valued in utility, explicit rules for several fiscal instruments, a maturity structure for nominal government debt, and steady-state distorting taxes.

\subsection{Firms And Price Setting}

The production sector consists of intermediate and final goods producing firms. A perfectly competitive final goods producer uses a continuum of intermediate goods $Y_{t}(i)$, where $i \in[0,1]$, to

produce the final goods $Y_{t}$, with the constant-return-to-scale technology $\left(\int_{0}^{1} Y_{t}(i)^{\frac{1}{1+\eta_{t}^{p}}} d i\right)^{1+\eta_{t}^{p}} \geq Y_{t}$, where $\eta_{t}^{p}$ denotes an exogenous, time-varying markup to the prices of intermediate goods.

The price of intermediate good $i$ is $\bar{P}_{t}(i)$ and the price of final goods $Y_{t}$ is $\bar{P}_{t}$. The final goods producing firm chooses $Y_{t}$ and $Y_{t}(i)$ to maximize profits subject to the constant-return-to-scale technology. Dixit-Stiglitz aggregation yields the demand $Y_{t}(i)=Y_{t}\left(\bar{P}_{t}(i) / \bar{P}_{t}\right)^{-\left(1+\eta_{t}^{p}\right) / \eta_{t}^{p}}$.

Intermediate goods producers are monopolistic competitors in their product market. Firm $i$ has access to the technology $Y_{t}(i)=K_{t}(i)^{\alpha}\left(A_{t} L_{t}(i)\right)^{1-\alpha}-A_{t} \Omega$, where $\alpha \in[0,1]$ and $\Omega>0$ represents 
fixed costs to production that grow at the rate of technological progress. $A_{t}$ is a permanent shock to technology. The logarithm of its growth rate, $u_{t}^{a}=\ln A_{t}-\ln A_{t-1}$, follows the stationary $\operatorname{AR}(1)$ process $u_{t}^{a}=\left(1-\rho_{a}\right) \gamma+\rho_{a} u_{t-1}^{a}+\epsilon_{t}^{a}, \epsilon_{t}^{a} \sim N\left(0, \sigma_{a}^{2}\right)$, where $\gamma$ defines the logarithm of the steadystate gross growth rate of technology. Firms face perfectly competitive factor markets for capital and labor. Cost minimization implies that the firms have identical nominal marginal costs per unit of output, $M C_{t}=(1-\alpha)^{\alpha-1} \alpha^{-\alpha}\left(R_{t}^{k}\right)^{\alpha} W_{t}^{1-\alpha} A_{t}^{-1+\alpha}$.

Prices evolve by a Calvo (1983) mechanism. An intermediate firm faces probability $\left(1-\omega_{p}\right)$ each period that it may reoptimize its price. Firms that cannot reoptimize partially index their prices to past inflation according to the rule $P_{t}(i)=\left(\pi_{t-1}\right)^{\chi_{p}}(\pi)^{1-\chi_{p}} P_{t-1}(i)$, where $\pi_{t-1} \equiv P_{t-1} / P_{t-2}$ is the inflation rate, $\pi$ is the steady state inflation rate, and $\chi_{p} \in[0,1]$.

Firms that reoptimize their price in period $t$ maximize expected discounted nominal profits subject to the demand for $Y_{t}(i)$. Given the production function, average and marginal costs coincide, which allows expected discounted nominal profits to be written as

$$
E_{t} \sum_{s=0}^{\infty}\left(\beta \omega_{p}\right)^{s} \frac{\lambda_{t+s}}{\lambda_{t}}\left[\left(\prod_{k=1}^{s} \pi_{t+k-1}^{\chi_{p}} \pi^{1-\chi_{p}}\right) P_{t}(i) Y_{t+s}(i)-M C_{t+s} Y_{t+s}(i)\right]
$$

where $\lambda$ is the marginal utility of wealth of saver households, defined below.

2.1.1 LABOR AGENCY Each household supplies a continuum of differentiated labor services indexed by $l$. These differentiated labor services are supplied by both savers and non-savers, and demand is uniformly allocated among households. A competitive labor agency combines the differentiated labor services into a homogenous labor input that is sold to intermediate firms, according to the technology $L_{t}=\left(\int_{0}^{1} L_{t}(l)^{\frac{1}{1+\eta_{t}^{w}}} d l\right)^{1+\eta_{t}^{w}}$ where $\eta_{t}^{w}$ denotes a time-varying exogenous markup to wages. The competitive labor agency's demand function comes from solving its profit maximization problem, which yields $L_{t}(l)=L_{t}^{d}\left(W_{t}(l) / W_{t}\right)^{-\left(1+\eta_{t}^{w}\right) / \eta_{t}^{w}}$ where $L_{t}^{d}$ is the demand for composite labor services, which is given by intermediate firms, and $W_{t}$ is the aggregate nominal wage that satisfies $W_{t}=\left(\int_{0}^{1} W_{t}(l)^{\frac{1}{\eta_{t}^{w}}} d l\right)^{\eta_{t}^{w}}$.

\subsection{Households}

The economy is populated by a continuum of households on the interval $[0,1]$, of which a fraction $\mu$ are non-savers and a fraction $1-\mu$ are savers. Superscript $S$ indicates a variable associated with savers and $N$ with non-savers.

2.2.1 SAvers An optimizing saver household $j$ derives utility from composite consumption, $C^{* S}(j)$, consisting of private $C_{t}^{S}(j)$ and public $G_{t}$ consumption goods, $C^{* S}(j) \equiv C_{t}^{S}(j)+\alpha_{G} G_{t}$. Parameter $\alpha_{G}$ governs the degree of substitutability of the consumption goods: when $\alpha_{G}<0$, private and public consumption are complements; when $\alpha_{G}>0$, the goods are substitutes. The household values consumption relative to a habit stock defined in terms of lagged aggregate consumption of savers $\left(\theta \tilde{C}_{t-1}^{* S}\right.$ where $\left.\theta \in[0,1)\right)$. Each household $j$ supplies a continuum of differentiated labor 
inputs, $L_{t}^{S}(j, l), l \in[0,1]$. The aggregate quantity of these labor services is $L_{t}^{S}(j) \equiv \int_{0}^{1} L_{t}^{S}(j, l) d l$. Households maximize lifetime utility $E_{t} \sum_{t=0}^{\infty} \beta^{t} u_{t}^{b}\left(\ln \left(C_{t}^{* S}(j)-\theta \tilde{C}_{t-1}^{* S}\right)-\left(L_{t}^{S}(j)^{1+\xi}\right) /(1+\xi)\right)$, where $\beta$ is the discount rate, $\xi$ is the inverse of the Frisch labor elasticity and $u_{t}^{b}$ is an exogenous shock to preferences.

Savers have access to one-period nominal private bonds, $B_{s, t}$, that pay 1 unit of currency in $t+1$, sell at price $R_{t}^{-1}$ in $t$, and are in zero net supply. They also have access to a portfolio of long-term nominal government bonds, $B_{t}$, which sells at price $P_{t}^{B}$ in $t$. Maturity of these zero-coupon bonds decays at the constant rate $\rho \in[0,1]$ to yield the duration $(1-\beta \rho)^{-1}$.

Savers receive after-tax wage and rental income, lump-sum transfers from the government $Z^{S}$, and profits from firms $D$. Savers spend income on consumption, investment in future capital $I^{S}$, and government bonds. The nominal flow budget constraint for saver $j$ is

$$
\begin{aligned}
& P_{t}\left(1+\tau_{t}^{C}\right) C_{t}^{S}(j)+P_{t} I_{t}^{S}(j)+P_{t}^{B} B_{t}(j)+R_{t}^{-1} B_{s, t}(j)=\left(1+\rho P_{t}^{B}\right) B_{t-1}(j)+B_{s, t-1}(j) \\
& +\left(1-\tau_{t}^{L}\right) \int_{0}^{1} W_{t}(l) L_{t}^{S}(j, l) d l+\left(1-\tau_{t}^{K}\right) R_{t}^{k} v_{t}(j) \bar{K}_{t-1}^{S}(j)-\psi\left(v_{t}\right) \bar{K}_{t-1}^{S}+P_{t} Z_{t}^{S}(j)+D_{t}(j)
\end{aligned}
$$

Nominal consumption, $P^{C} C$, is subject to a sales $\operatorname{tax} \tau^{C} . W_{t}(l)$ is the nominal wage rate for labor input $l$, and $\int_{0}^{1} W_{t}(l) L_{t}^{S}(j, l) d l$ is the total nominal labor income for household $j$, which is taxed at the rate $\tau^{L}$. Since each saver-type household supplies all differentiated labor inputs in the economy, all saver households have the same total after-tax labor income in equilibrium.

Effective capital is related to the physical capital stock $\bar{K}$ by $K_{t}^{s}(j)=v_{t}(j) \bar{K}_{t-1}^{S}(j)$, where $v_{t}(j)$ is the utilization rate of capital. Utilization incurs a cost of $\Psi\left(v_{t}\right)$ per unit of physical capital. In steady state, $v=1$ and $\Psi(1)=0$. We define the parameter $\psi \in[0,1)$ such that $\frac{\Psi^{\prime \prime}(1)}{\Psi^{\prime}(1)} \equiv \frac{\psi}{1-\psi}$, as in Smets and Wouters (2003). As $\psi \rightarrow 1$, utilization costs become infinite, and the capital utilization rate becomes constant. Rental income on effective capital is taxed at the rate $\tau^{K}$. Capital obeys the law of motion

$$
\bar{K}_{t}^{S}(j)=(1-\delta) \bar{K}_{t-1}^{S}(j)+u_{t}^{i}\left[1-s\left(\frac{I_{t}^{S}(j)}{I_{t-1}^{S}(j)}\right)\right] I_{t}^{S}(j)
$$

where $s(\cdot) I_{t}^{S}$ is an investment adjustment cost, as in Smets and Wouters (2003) and Christiano et al. (2005) and satisfies $s^{\prime}\left(e^{\gamma}\right)=0$, and $s^{\prime \prime}\left(e^{\gamma}\right) \equiv s>0$. Investment costs decrease as $s$ declines and are subject to an investment-specific efficiency shock $u_{t}^{i}$.

Saver households reset their nominal wages for each differentiated labor service with probability $\left(1-\omega_{w}\right)$ each period. Wages that cannot be reoptimized are partially indexed to past inflation according to the rule $W_{t}(l)=W_{t-1}(l)\left(\pi_{t-1} e^{u_{t-1}^{a}}\right)^{\chi^{w}}\left(\pi e^{\gamma}\right)^{1-\chi_{w}}$, where $\chi^{w} \in[0,1]$ measures the degree of indexation. When wages are reset, households choose the nominal wage rate $W_{t}(l)$ to maximize their utility.

2.2.2 NON-SAVERS Non-savers have the same preferences as savers. Non-savers are rule-ofthumb agents who consume their entire disposable income each period, which consists of after-tax labor income and lump-sum transfers from the government $Z^{N}$. Like savers, non-savers supply all 
differentiated labor services. The budget constraint for a non-saver $j \in(\mu, 1]$ is

$$
\left(1+\tau_{t}^{C}\right) P_{t} C_{t}^{N}(j)=\left(1-\tau_{t}^{l}\right) \int_{0}^{1} W_{t}(l) L_{t}^{N}(j, l) d l+P_{t} Z_{t}^{N}(j)
$$

Substantial variation in modeling wage-setting decisions exists in the literature. We assume that savers optimally set wage rates, while non-savers follow a rule-of-thumb to set their wage rates to be the average wage rates chosen by savers, as in Erceg et al. (2006) and Forni et al. (2009). Since non-savers face the same labor demand schedule as savers, they work the same number of hours as the average for savers.

Non-savers' nominal consumption $P^{C} C^{N}$ is taxed at the same rate as savers, $\tau^{C}$, and their nominal wage income is taxed at the same rate as savers, $\tau^{L}$. Because non-savers elastically meet the demand for their labor and set their nominal wages according to savers' optimization, budget constraint (2) determines non-savers' consumption.

\subsection{Monetary \& Fiscal Policy}

The monetary authority follows a Taylor-type rule, in which the nominal interest rate $R_{t}$ responds to its lagged value, the current inflation rate, and current output. We denote a variable in percentage deviations from steady state by a hat. The interest rate obeys $\hat{R}_{t}=\rho_{r} \hat{R}_{t-1}+\left(1-\rho_{r}\right)\left[\phi_{\pi} \hat{\pi}_{t}+\phi_{y} \hat{Y}_{t}\right]+$ $u_{t}^{m}$, where $u^{m}$ is a monetary policy shock, defined by the process $u_{t}^{m}=\rho_{e m} u_{t-1}^{m}+\epsilon_{t}^{m}, \quad \epsilon_{t}^{m} \sim$ $N\left(0, \sigma_{m}^{2}\right)$.

The government collects tax revenues from capital, labor, and consumption taxes, and sells the nominal bond portfolio, $B_{t}$, to finance its interest payments and expenditures, $G_{t}, Z_{t}^{S}, Z_{t}^{N}$. Fiscal choices satisfy the identity $P_{t}^{B} B_{t}+\tau_{t}^{K} R_{t}^{K} K_{t}+\tau_{t}^{L} W_{t} L_{t}+P_{t} \tau_{t}^{C} C_{t}=\left(1+\rho P_{t}^{B}\right) B_{t-1}+P_{t} G_{t}+P_{t} Z_{t}$, where lump-sum transfers are assumed to be identical across households, so that $Z_{t}=\int_{0}^{1} Z_{t}(j) d j=$ $Z_{t}^{S}=Z_{t}^{N}$.

Fiscal rules are simple. They include a response of fiscal instruments to the market value of the debt-to-GDP ratio - to ensure that policies stabilize debt - and an autoregressive term to allow for serial correlation. Fiscal instruments follow the rules

$\hat{G}_{t}=\rho_{G} \hat{G}_{t-1}-\left(1-\rho_{G}\right) \gamma_{G} \hat{s}_{t-1}^{b}+u_{t}^{G}, \quad \hat{Z}_{t}=\rho_{Z} \hat{Z}_{t-1}-\left(1-\rho_{Z}\right) \gamma_{Z} \hat{s}_{t-1}^{b}+u_{t}^{Z}, \quad \hat{\tau}_{t}^{\mathcal{J}}=\rho_{\mathcal{J}} \hat{\tau}_{t-1}^{\mathcal{J}}+\left(1-\rho_{\mathcal{J}}\right) \gamma_{\mathcal{J}} \hat{s}_{t-1}^{b}$,

where $\mathcal{J}=K, L, s_{t-1}^{b} \equiv \frac{P_{t-1}^{B} B_{t-1}}{P_{t-1} Y_{t-1}}, u_{t}^{s}=\rho_{e s} u_{t-1}^{s}+\epsilon_{t}^{s}$ and $\epsilon_{t}^{s} \sim N\left(0, \sigma_{s}^{2}\right)$ for $s=\{G, Z\}$. Consumption taxes are restricted to a constant, steady state value. ${ }^{4}$

\subsection{AgGregation}

Aggregate consumption is $C_{t}=\int_{0}^{1} C_{t}(j) d j=(1-\mu) C_{t}^{S}+\mu C_{t}^{N}$. Because only savers have access to the asset and capital markets, aggregate bonds, private capital, investment, and dividends are

\footnotetext{
${ }^{4}$ We do not allow consumption taxes to respond to debt. In U.S. federal government data, consumption taxes consist of excise taxes and custom duties, which average one percent of GDP. The online appendix documents that consumption tax financing has little quantitative effect on multipliers.
} 


\begin{tabular}{ll}
\hline & Parameter Restrictions \\
\hline Model 1: RBC Real Frictions & $\omega_{w}=\omega_{p}=\eta^{w}=\eta^{p}=\chi_{w}=\chi_{p}=\phi_{\pi}=\phi_{y}=\rho_{r}=\mu=\alpha_{G}=0$ \\
Model 2: New Keynesian & $\mu=\alpha_{G}=0$ \\
Model 3: New Keynesian Nonsavers & $\alpha_{G}=0$ \\
Model 4: New Keynesian G in Util & $\mu=0$ \\
\hline
\end{tabular}

Table 1: Parameter restrictions on the general prior predictive model that deliver nested models.

$\Upsilon_{t}=\int_{0}^{1-\mu} \Upsilon_{t}(j) d j$ for $\Upsilon=\{B, K, I, D\}$. The goods market clearing condition is $Y_{t}=C_{t}+I_{t}+G_{t}+$ $\psi\left(v_{t}\right) \bar{K}_{t-1}$.

\subsection{Nested Models}

Our broad model nests models that are commonly used to examine the size of the fiscal multiplier. Table 1 lists the specific parameter restrictions that deliver each of the five nested models. Model 1 eliminates all nominal frictions $\left(\omega_{w}=\omega_{p}=\eta^{w}=\eta^{p}=\chi_{w}=\chi_{p}=0\right)$ and monetary policy $\left(\phi_{\pi}=\phi_{y}=\rho_{r}=0\right)$ to reduce to a standard RBC model. Model 2 is a standard new Keynesian model with sticky prices and wages, which introduces a role for monetary-fiscal policy interactions. Model 3 adds non-savers to the standard new Keynesian model. Model 4 eliminates non-savers and allows instead for government spending to be non-separable in the utility function. ${ }^{5}$

\section{Prior Predictive Analysis}

Simple DSGE models that permit analytical calculations of the multiplier are important for building economic intuition [Uhlig (2010), Woodford (2011)], but they tend to be too simple to take to data. Models that include real and nominal frictions, which fit data well, do not yield clean analytics. We echo Geweke (2010) and Faust and Gupta (2010) in arguing for the use of prior predictive analysis to shed light on the black-box nature of empirically validated DSGE models. Prior predictive analysis pinpoints precisely which elements of a model are critical to determine fiscal multipliers and it delivers the range of multipliers that a specific model can produce. We use the results of the prior predictive analysis to determine which models to take to the data. We also show that many of the DSGE models that have played a role in the fiscal policy debate impose tight ranges on fiscal multipliers a priori [section 3.5].

This section lays out the prior predictive technique and the priors that we employ. After defining the government spending multipliers that we report throughout the paper, the section reports statistics that summarize the prior predictive distributions of multipliers across a wide variety of model specifications.

\footnotetext{
${ }^{5}$ We restrict the exposition to a closed economy. See Leeper et al. (2011) and the online appendix for open-economy versions of the model. Opening the economy tends to reduce government spending multipliers.
} 


\subsection{Prior Predictive Technique}

Prior predictive analysis entails four steps: ${ }^{6}$

i. Given a DSGE model, $A_{j}$, and associated model parameters, $\theta_{A_{j}}$, for $j=1,2, \ldots, n$, we posit a prior density function $p\left(\theta_{A_{j}} \mid A_{j}\right)$, which specifies the range of values and the probabilities that the parameters take those values. Calibration is an example of a degenerate or dogmatic prior density. We assume that the parameters are drawn independently, and let $\tilde{p}\left(\theta_{A_{j}} \mid A_{j}\right)$ be the product of the marginal parameter distributions. We restrict analysis to the parameter subspace that delivers a unique rational expectations equilibrium and denote this subspace as $\Theta_{D_{j}}$. Let $\mathcal{I}\left\{\theta_{A_{j}} \in \Theta_{D_{j}}\right\}$ be an indicator function that is one if $\theta_{A_{j}}$ is in the determinacy region and zero otherwise. Then, the joint prior distribution is defined as $p\left(\theta_{A_{j}} \mid A_{j}\right)=\frac{1}{c} \tilde{p}\left(\theta_{A_{j}} \mid A_{j}\right) \mathcal{I}\left\{\theta_{A_{j}} \in \Theta_{D_{j}}\right\}$, where $c=\int_{\theta_{A_{j}} \in \Theta_{D_{j}}} \tilde{p}\left(\theta_{A_{j}} \mid A_{j}\right) d \theta_{A_{j}}$

ii. The log-linearized DSGE model that section 2 describes and the nested models in table 1 constitute the set of models under consideration. Those models generate ex-ante predictive distributions for the models' observables, $y_{T}$, from $p\left(y_{T} \mid A_{j}\right)=\int_{\Theta_{A_{j}}} p\left(\theta_{A_{j}} \mid A_{j}\right) p\left(y_{T} \mid \theta_{A_{j}} A_{j}\right) d \theta_{A_{j}}$

iii. We specify a vector of interest, $\omega$, with corresponding distribution $p\left(\omega_{T} \mid y_{T}, \theta_{A_{j}}, A_{j}\right)$. Our vector of interest consists of various measures of the fiscal multiplier, which we define in section 3.4. As the conditional distribution makes explicit, the fiscal multiplier depends on the choice of model $\left(A_{j}\right)$, model-implied observables $\left(y_{T}\right)$, and parameters $\left(\theta_{A_{j}}\right)$.

iv. To generate prior predictive distributions for fiscal multipliers, the algorithm draws from $\theta_{A_{j}}^{(m)} \sim$ $p\left(\theta_{A_{j}} \mid A_{j}\right)$, and $y_{T}^{(m)} \sim p\left(y_{T} \mid \theta_{A_{j}}^{(m)}, A_{j}\right)$. Drawing sequentially from these distributions delivers $p\left(y_{T} \mid A_{j}\right)$ and any function of $y_{T}$ including the vector of interest, $\omega^{(m)}$. A model specification and a prior distribution produce prior distributions for fiscal multipliers.

The distribution $p\left(y_{T} \mid A_{j}\right)$ gives the prior distribution of observables, which implies the distribution of fiscal multipliers, $p\left(\omega_{T} \mid y_{T}, \theta_{A_{j}}, A_{j}\right)$. Computationally, it is straightforward and nearly costless to simulate from $p\left(y_{T} \mid A_{j}\right)$. Given a prior density over model parameters, prior predictive analysis produces the entire range of a model's possible multipliers, to shed light on a model's predictions before confronting data. This narrows the set of models to estimate. For example, if prior predictive analysis suggests that it is nearly impossible for a model to produce large multipliers, then conclusions drawn from estimates of that model need to be tempered by the fact that regardless of the information in actual data, the model will imply that multipliers are small. Prior predictive analysis helps to gauge whether such a model is appropriate to study the magnitude of fiscal multipliers.

\footnotetext{
${ }^{6}$ These steps follow Geweke (2010, Chapter 3).
} 


\subsection{Prior Distributions}

In all model specifications we fix a few parameters. The discount factor, $\beta$, is set to 0.99 . The capital income share of total output, $\alpha$, is set to 0.33 . The quarterly depreciation rate for private capital, $\delta$, is set to 0.025 so that the annual depreciation rate is 10 percent. Steady state inflation, $\pi$, is 1 . Because the price and wage markups cannot be separately identified in the estimation, we calibrate them as $\eta_{w}=\eta_{p}=0.14$.

Steady-state fiscal variables are calibrated to the mean values from U.S. data over the period 1955q1-2014q2. Federal government consumption as a share of model output (that is, GDP excluding net exports) is 0.11 , the federal debt to annualized model output share is 1.47 , the average federal labor tax rate is 0.186 , the capital tax rate is 0.218 , and the consumption tax rate is 0.023 . See the online appendix for details of the data construction.

Table 2 lists the priors. The prior distributions cover a broad range of parameter values and are similar to those employed for Bayesian estimation of models closely related to ours [Coenen and Straub (2005), Forni et al. (2009), Lopez-Salido and Rabanal (2006), Leeper et al. (2010), Drautzburg and Uhlig (2013), Fève et al. (2013), Zubairy (2014), and Traum and Yang (2015)]. An important difference is that we adopt priors over nominal rigidities and habit formationparameters $\omega_{p}, \omega_{w}$, and $\theta$ in the table - with somewhat broader support. The prior predictive analysis tells us which model/parameter specification permits a wide range of fiscal multipliers. An agnostic a priori view of the signs and sizes of multipliers is an essential step toward clearing up the multiplier morass. To avoid prejudging the estimation results, we use an equally agnostic prior to obtain the posterior distribution.

\subsection{Policy Regimes}

In versions of our model that integrate monetary and fiscal policies, two distinct regions of the parameter subspace deliver unique bounded rational expectations equilibria - an active monetary/passive fiscal policy regime (regime M) or a passive monetary/active fiscal policy regime (regime F). To reflect these two policy regimes, we consider two sets of policy parameter priors: the first places nearly all probability mass on regions of the parameter space consistent with regime $\mathrm{M}$ and the second does the same for regime $\mathrm{F}$. In regime $\mathrm{M}$ the monetary authority raises the interest rate aggressively in response to inflation while the fiscal authority adjusts expenditures and tax rates to stabilize debt. Regime F has monetary policy responding only weakly to inflation, while fiscal instruments react only weakly to government debt. The two regimes appear in table 2 as different priors on $\phi_{\pi}$ in the monetary policy rule and on the $\gamma_{i}$ 's in the fiscal rules. The priors assign a small, non-zero density outside the determinacy regions of the parameter space, so we restrict the parameter space to the subspaces in which the log-linearized model has a unique bounded rational expectations solution by discarding draws from the indeterminacy region. 


\begin{tabular}{|c|c|c|c|c|}
\hline \multirow[t]{2}{*}{ Parameter } & \multicolumn{4}{|c|}{ Prior } \\
\hline & distribution & mean & std. & $90 \%$ int. \\
\hline \multicolumn{5}{|l|}{ Preference and $\mathrm{HHs}$} \\
\hline $100 \gamma$, ss $\ln$ growth rate & $\mathrm{N}$ & 0.4 & 0.05 & {$[0.42,0.58]$} \\
\hline$\xi$, inverse Frisch labor elast. & G & 2 & 0.5 & {$[1.18,2.80]$} \\
\hline$\theta$, habit formation & $\mathrm{B}$ & 0.5 & 0.2 & {$[0.17,0.83]$} \\
\hline$\mu$, fraction of non-savers & $\mathrm{B}$ & 0.3 & 0.1 & {$[0.14,0.46]$} \\
\hline$\alpha_{G}$, substitutability of private/public cons. & $\mathrm{U}$ & 0 & 1.01 & {$[-1.58,1.58]$} \\
\hline \multicolumn{5}{|l|}{ Frictions and Production } \\
\hline$\psi$, capital utilization & B & 0.6 & 0.15 & {$[0.36,0.85]$} \\
\hline$s$, investment adj. cost & $\mathrm{N}$ & 6 & 1.5 & {$[3.54,8.47]$} \\
\hline$\omega_{p}$, price stickiness & $\mathrm{B}$ & 0.5 & 0.2 & {$[0.17,0.83]$} \\
\hline$\omega_{w}$, wage stickiness & $\mathrm{B}$ & 0.5 & 0.2 & {$[0.17,0.83]$} \\
\hline$\chi_{p}$, price partial indexation & $\mathrm{B}$ & 0.5 & 0.2 & {$[0.17,0.83]$} \\
\hline$\chi w$, wage partial indexation & $\mathrm{B}$ & 0.5 & 0.2 & {$[0.17,0.83]$} \\
\hline \multicolumn{5}{|l|}{ Monetary policy } \\
\hline$\phi_{\pi}$, interest rate resp. to inflation, Regime $\mathrm{M}$ & $\mathrm{N}$ & 1.5 & 0.2 & {$[1.17,1.83]$} \\
\hline$\phi_{\pi}$, interest rate resp. to inflation, Regime $\mathrm{F}$ & $\mathrm{B}$ & 0.5 & 0.15 & {$[0.25,0.75]$} \\
\hline$\phi_{y}$, interest rate resp. to output & $\mathrm{N}$ & 0.125 & 0.05 & {$[0.04,0.21]$} \\
\hline$\rho_{r}$, resp. to lagged interest rate & $\mathrm{B}$ & 0.5 & 0.2 & {$[0.17,0.83]$} \\
\hline \multicolumn{5}{|l|}{ Fiscal policy } \\
\hline$\gamma_{i}$, debt responses for $i=G, K, L, Z$, Regime $\mathrm{M}$ & $\mathrm{N}$ & 0.15 & 0.1 & {$[-0.015,0.31]$} \\
\hline$\gamma_{i}$, debt responses for $i=G, K, L, Z$, Regime $\mathrm{F}$ & $\mathrm{N}$ & 0 & 0.001 & {$[-0.0016,0.0016]$} \\
\hline$\rho_{i}$, lagged resp. for $i=G, K, L, Z$ & $\mathrm{~B}$ & 0.5 & 0.2 & {$[0.17,0.83]$} \\
\hline \multicolumn{5}{|l|}{ Shocks } \\
\hline$\rho_{a}$, technology & $\mathrm{B}$ & 0.5 & 0.2 & {$[0.17,0.83]$} \\
\hline$\rho_{b}$, preference & B & 0.5 & 0.2 & {$[0.17,0.83]$} \\
\hline$\rho_{i}$, investment & $\mathrm{B}$ & 0.5 & 0.2 & {$[0.17,0.83]$} \\
\hline$\rho_{p}$, price markup & $\mathrm{B}$ & 0.5 & 0.2 & {$[0.17,0.83]$} \\
\hline$\rho_{w}$, wage markup & $\mathrm{B}$ & 0.5 & 0.2 & {$[0.17,0.83]$} \\
\hline$\rho_{\text {em }}$, monetary policy & $\mathrm{B}$ & 0.5 & 0.15 & {$[0.25,0.75]$} \\
\hline$\rho_{e g}$, govt cons & $\mathrm{B}$ & 0.5 & 0.15 & {$[0.25,0.75]$} \\
\hline$\rho_{e z}$, transfers & $\mathrm{B}$ & 0.5 & 0.15 & {$[0.25,0.75]$} \\
\hline $100 \sigma_{a}$, technology & Inv. Gamma & 0.1 & 1 & {$[0.01,0.19]$} \\
\hline $100 \sigma_{b}$, preference & Inv. Gamma & 0.1 & 1 & {$[0.01,0.19]$} \\
\hline $100 \sigma_{m}$, monetary policy & Inv. Gamma & 0.1 & 1 & {$[0.01,0.19]$} \\
\hline $100 \sigma_{i}$, investment & Inv. Gamma & 0.1 & 1 & {$[0.01,0.19]$} \\
\hline $100 \sigma_{p}$, price markup & Inv. Gamma & 0.1 & 1 & {$[0.01,0.19]$} \\
\hline $100 \sigma_{w}$, wage markup & Inv. Gamma & 0.1 & 1 & {$[0.01,0.19]$} \\
\hline $100 \sigma_{G}$, govt cons & Inv. Gamma & 0.1 & 1 & {$[0.01,0.19]$} \\
\hline $100 \sigma_{Z}$, transfers & Inv. Gamma & 0.1 & 1 & {$[0.01,0.19]$} \\
\hline
\end{tabular}

Table 2: Prior distributions.

Cochrane (2001), Sims (2013) and Leeper and Leith (2017) show that in regime F, long-term nominal government debt can have important effects on inflation dynamics. When prices and wages are sticky, dynamics of real variables will also be affected by the presence of long debt, so we examine specifications with one-period debt - the typical assumption in the literature - and with a fixed duration of five years. Maturity structure is irrelevant in regime $\mathrm{M}$ when all fiscal financing is lump sum and Ricardian equivalence holds; otherwise, maturity structure can matter even in regime $\mathrm{M}$.

\subsection{Multiplier Definition}

Present-value multipliers, which embody the full dynamics associated with exogenous fiscal actions and properly discount future macroeconomic effects, constitute our vector of interest. The present value of additional output, $Y_{t+k}$, over a $k$-period horizon produced by an exogenous change in the present value of government spending is

$$
\text { Present Value Multiplier }(k)=\frac{E_{t} \sum_{j=0}^{k}\left(\prod_{i=0}^{k}\left(1+r_{t+i}\right)^{-1}\right) \Delta Y_{t+j}}{E_{t} \sum_{j=0}^{k}\left(\prod_{i=0}^{k}\left(1+r_{t+i}\right)^{-1}\right) \Delta G_{t+j}}
$$


where $r_{t+i}$ is the model-implied real interest rate. Private consumption and investment multipliers are defined analogously. At $k=0$ the present-value multiplier equals the impact multiplier. Because a present-value multiplier is cumulative, its value at $t+k$ reports the total effect over $k$ periods of a change in spending at time $t$.

\subsection{Likelihood of Large Multipliers}

To compare multipliers across models, we focus on prior predictive $p$-values, which report the probability of observing a multiplier greater than a particular value in repeated sampling from the model and prior. Tables 3 and 4 compare output, consumption and investment multiplier $p$-values at various horizons across the four model specifications and variants within those specifications. Table 3 reports the probability that present-value multipliers for output exceed unity at various horizons. The top panel of table 4 records the probability that multipliers for consumption exceed 0 , while the bottom panel reports the same information about investment multipliers. These probabilities reflect how likely a particular specification is to generate large multipliers, independent of any information in data.

We examine four broad model specifications: a real business cycle model with frictions; a basic new Keynesian model with sticky prices and wages; an extension of the new Keynesian model that adds non-saving rule-of-thumb agents; and a new Keynesian model that eliminates rule-ofthumb agents, but permits government purchases to enter utility directly, either as a substitute or a complement. The three monetary models include both regime $\mathrm{M}$ and regime $\mathrm{F}$ monetaryfiscal policy regimes. Because the presence of long-maturity debt matters in regime $\mathrm{F}$ for inflation and output dynamics, those specifications are subdivided between short debt and long debt. ${ }^{7}$ To shed light on the estimation results that appear in section 4.2, we consider several fiscal variants on model 4 in which government purchases enter utility: all fiscal instruments - capital and labor tax rates, government purchases, and government transfers - respond to government debt; only purchases and transfers respond to debt but tax distortions enter the steady state (labeled "ss tax only" in the tables); purchases and transfers respond to debt but steady state taxes rates are set to zero (labeled "no tax"). The last fiscal variant often appears in multiplier studies and implies negative transfers, or lump-sum taxation.

We start by examining the real business cycle model with flexible prices and real frictions that include habit formation, investment adjustment costs, and capacity utilization (model 1 in tables 3 and 4). ${ }^{8}$ It is impossible for this model to generate output multipliers greater than one or to produce positive consumption multipliers at any horizon. A persistent increase in government spending creates a negative wealth effect, as taxes are expected to increase in the future to finance

\footnotetext{
${ }^{7}$ See the online appendix for a comparison of multipliers in regime $\mathrm{M}$ with short and long debt. At longer horizons, a longer maturity often implies higher multipliers, but the differences are small compared to regime F.

${ }^{8}$ An earlier draft reports these probabilities for the basic RBC model without frictions [Leeper et al. (2011)]. That basic model is similar to Baxter and King (1993), Monacelli and Perotti (2008), Uhlig (2010) and Woodford (2011), with the addition of distortionary fiscal financing, as in Leeper et al. (2010), so it has been extensively studied. For space reasons, we exclude it.
} 


\begin{tabular}{|c|c|c|c|c|c|c|}
\hline & & Impact & 4 qtrs & 10 qtrs & 25 qtrs & 10 years \\
\hline Model 1: & RBC Real Frictions & 0.00 & 0.00 & 0.00 & 0.00 & 0.00 \\
\hline \multirow[t]{4}{*}{ Model 2: } & New Keynesian Sticky Prices \& Wages & & & & & \\
\hline & Regime $M$ & 0.12 & 0.01 & 0.00 & 0.01 & 0.01 \\
\hline & Regime F, short debt & 1.00 & 0.98 & 0.94 & 0.92 & 0.92 \\
\hline & Regime $F$, long debt & 0.96 & 0.79 & 0.68 & 0.68 & 0.68 \\
\hline \multirow[t]{4}{*}{ Model 3: } & New Keynesian Nonsavers & & & & & \\
\hline & Regime $M$ & 0.59 & 0.22 & 0.06 & 0.04 & 0.04 \\
\hline & Regime F, short debt & 1.00 & 1.00 & 0.97 & 0.95 & 0.94 \\
\hline & Regime F, long debt & 1.00 & 0.94 & 0.81 & 0.77 & 0.76 \\
\hline \multirow[t]{13}{*}{ Model 4: } & New Keynesian G-in-Utility & & & & & \\
\hline & Regime $M$, substitutes & 0.00 & 0.00 & 0.00 & 0.00 & 0.00 \\
\hline & Regime $M$, complements & 0.84 & 0.69 & 0.49 & 0.31 & 0.25 \\
\hline & Regime $M$, complements, ss tax only & 0.84 & 0.69 & 0.54 & 0.47 & 0.47 \\
\hline & Regime $M$, complements, no tax & 0.86 & 0.72 & 0.56 & 0.51 & 0.52 \\
\hline & Regime $F$, substitutes, short debt & 0.43 & 0.48 & 0.66 & 0.79 & 0.81 \\
\hline & Regime F, substitutes, long debt & 0.23 & 0.18 & 0.21 & 0.39 & 0.45 \\
\hline & Regime F, complements, short debt & 1.00 & 1.00 & 1.00 & 0.98 & 0.97 \\
\hline & Regime F, complements, long debt & 1.00 & 0.98 & 0.93 & 0.89 & 0.88 \\
\hline & Regime $F$, complements, short debt, ss tax only & 1.00 & 1.00 & 0.99 & 0.97 & 0.97 \\
\hline & Regime $F$, complements, long debt, ss tax only & 1.00 & 0.98 & 0.93 & 0.89 & 0.86 \\
\hline & Regime F, complements, short debt, no tax & 1.00 & 1.00 & 0.99 & 0.99 & 0.98 \\
\hline & Regime F, complements, long debt, no tax & 1.00 & 0.99 & 0.95 & 0.93 & 0.92 \\
\hline
\end{tabular}

Table 3: Government spending output multiplier probabilities implied by prior predictive analysis based on 20,000 draws from the prior distribution. Short debt is all one-period; long debt has 5-year duration. Substitutes (complements) restricts $\alpha_{G}>0(<0)$. In all cases except "ss tax only" and "no tax," government purchases, transfers, and distorting taxes on capital and labor may respond to government debt. "ss tax only" shuts down the distorting tax responses, but maintains positive steady state capital and labor taxes; "no tax" eliminates distorting taxes from the model-both dynamic responses and in steady state.

the new spending. Agents decrease consumption and work more. These wealth effects are reinforced by negative substitution effects. Real wages decrease with the increase in work effort and the rental price of capital increases with the rising marginal product of capital. Consumption and investment are likely to decrease, though their declines are tempered by real frictions in the model. ${ }^{9}$ Habit formation makes agents less willing to decrease consumption quickly as changes in consumption are costly. Investment adjustment costs and capacity utilization costs deter large swings in investment, offsetting some of the potential crowding out of investment. Despite these tempering forces, declines in private demand offset most of the increased public demand, causing output to increase by less than the increase in government consumption.

There is only a small probability that investment will increase at most horizons. This result is consistent across all regime $\mathrm{M}$ specifications, except in the short run when government purchases

\footnotetext{
${ }^{9}$ See Monacelli and Perotti (2008) for a more detailed examination of the effect of habit formation and investment adjustment costs on multipliers in a simple RBC model. Bilbiie (2009) shows non-separable preferences can give positive consumption multipliers but require consumption to be an inferior good. Fève et al. (2011) shows that a model with a labor externality can give positive consumption multipliers. Finn (1998) discusses how private and public consumption complementarity affect consumption in a RBC model.
} 
enter utility as substitutes for private consumption, as in model 4 in the bottom panel of table 4 . Apart from that exception, any possibility of higher investment stems from a subset of very high draws for $\rho_{G}$, the serial correlation of government spending. As $\rho_{G}$ approaches one, agents view an exogenous change in government spending as approximately permanent. Permanent increases in government consumption encourage households to save more, raising investment. This difference between permanent and temporary changes to public expenditures echoes earlier work, such as Aiyagari et al. (1992) and Baxter and King (1993). In the absence of a near-unity value of $\rho_{G}$ or sufficiently strong substitution of purchases for consumption, investment would never rise in regime M.

Model 2 introduces sticky prices and sticky wages, which increase output multipliers at all horizons, as Woodford (2011) shows analytically. Greater price stickiness means that more firms respond to higher government spending by increasing production rather than prices, so markups respond more strongly. Although the likelihood of large multipliers tapers off over time, in the long run there continues to be some small probability of sizeable multipliers in regime M. RBC models cannot produce these positive long-run multipliers; nominal rigidities are necessary for spending increases to persistently raise output.

Non-savers (model 3) raise fiscal multipliers substantially, a point that Galí et al. (2007), Furlanetto (2011), and Colciago (2011) emphasize. In this model, the fraction of non-savers is the most influential parameter for the output multiplier, as variations in this parameter are necessary to get mean impact output multipliers greater than one in regime M. Unlike savers, non-savers ignore the wealth effects of future taxes and consume their entire income each period. If wages are sticky, then real wages rise with government spending, increasing non-savers' consumption. With enough non-savers in the economy, the increase in non-saver consumption can be large enough to cause total consumption to increase on impact. ${ }^{10}$ Both the output and consumption effects in regime $\mathrm{M}$ are short-lived, with most of the increase in multipliers disappearing after two years.

In regime $\mathrm{M}$, permitting government spending to enter utility can consistently generate large multipliers, even in the long run (model 4). The effect is direct: when government purchases substitute for private consumption, higher purchases raise output, crowd out consumption and increase investment; when purchases complement consumption, output and consumption multipliers are likely to be large and fairly persistent. ${ }^{11}$ Higher consumption comes at the cost of lower investment. The preference parameter that determines the elasticity of substitution between government and private consumption, $\alpha_{G}$, is by far the most important parameter for determining the magnitude of multipliers within a given policy regime.

Across all model specifications, the monetary-fiscal policy regime is the dominant factor in determining government spending impacts: output, consumption and investment multipliers are

\footnotetext{
${ }^{10}$ Alternatively, Bilbiie (2011) and Monacelli and Perotti (2008) suggest non-separability in preferences over consumption and leisure also can produce positive consumption multipliers, as can deep habits, as shown by Ravn et al. (2006). Devereux et al. (1996) show an externality in production also can give large output responses.

${ }^{11}$ Models with public spending in the utility function have a long history, see for example Barro (1981), Aschauer (1985), Christiano and Eichenbaum (1992), McGrattan (1994), Finn (1998), and Linnemann and Schabert (2004).
} 


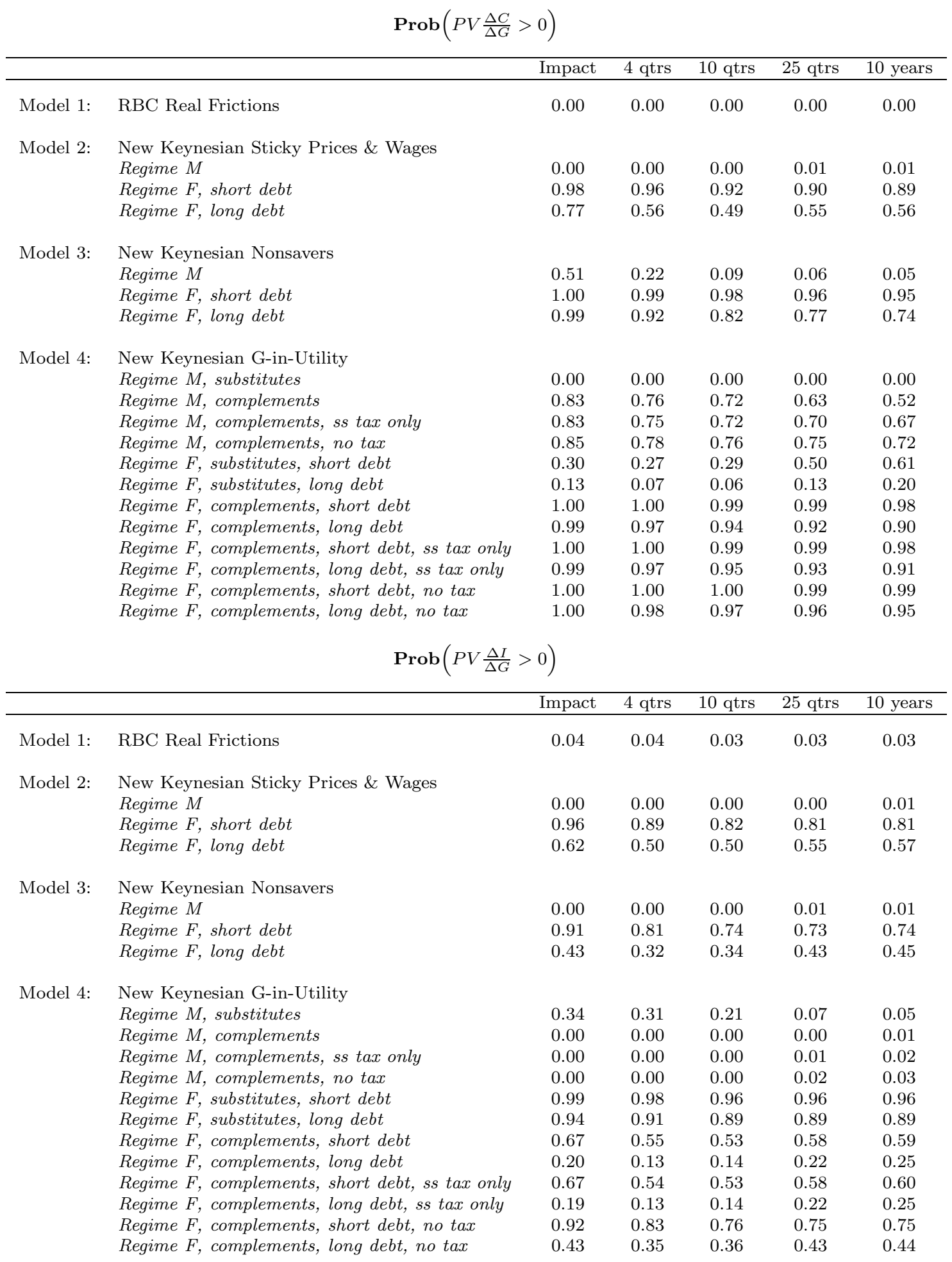

Table 4: Government spending consumption and investment multiplier probabilities implied by prior predictive analysis based on 20,000 draws from the prior distribution. Short debt is all oneperiod; long debt has 5-year duration. Substitutes (complements) restricts $\alpha_{G}>0(<0)$. In all cases except "ss tax only" and "no tax," government purchases, transfers, and distorting taxes on capital and labor may respond to government debt. "ss tax only" shuts down the distorting tax responses, but maintains positive steady state capital and labor taxes; "no tax" eliminates distorting taxes from the model — both dynamic responses and in steady state. 
far more likely to be large in regime $\mathrm{F}$ than in regime $\mathrm{M}$. Long-term debt reduces the probability of large multipliers in regime F, compared to when all debt is one-period. For example, even when $\alpha_{G}$ is restricted to being positive, so government spending substitutes for private consumption, there is a substantial probability of sizeable output and consumption multipliers in regime F; those probabilities are 0 in regime $\mathrm{M}$. Long-term debt cuts those probabilities in regime $\mathrm{F}$ by factors of between 2 and 5 .

Similar patterns emerge in models 2 (sticky prices and wages) and 3 (rule-of-thumb agents). Moving from regime $\mathrm{M}$ to regime $\mathrm{F}$ dramatically increases output and consumption multipliers at all horizons. While the likelihood of large multipliers with non-saving agents in regime $\mathrm{M}$ tapers off sharply beyond horizons of four quarters, in regime $\mathrm{F}$ the tapering off is barely discernible. Once again, though, long debt systematically reduces the probability of realizing large multipliers.

In regime $\mathrm{F}$, large consumption multipliers do not come at the expense of lower investment, as is true in regime M. All regime F specifications produce a high probability of positive investment multipliers along with positive consumption effects. The least likely specifications to generate positive investment impacts combine two factors: government and private consumption are complements and distorting taxes are present, either in steady state or dynamically responding to increases in debt. Even in those cases, positive investment effects occur in about 20 percent of the parameter draws in regime F. Eliminating steady-state taxes increases the likelihood of large multipliers for all three variables.

\subsection{Prior Predictive for Model Selection}

Rule-of-thumb agents are prevalent in models of government spending multipliers. Models that include a sufficiently large fraction of such agents are likely to produce sizeable output and consumption multipliers in the short run in both policy regimes, as tables 3 and 4 show. ${ }^{12}$ In contrast, when government spending enters utility, both a broader range and a larger persistence of multipliers are possible, depending on whether the spending substitutes for or complements private consumption. This information gleaned from the prior predictive helps to select a model specification with which to confront data.

Figure 1 reports prior means and 90-percent probability bands for multipliers in regime $\mathrm{M}$ for models with rule-of-thumb agents (dashed and dotted-dashed lines) and government-spending-inutility (solid lines); figure 2 repeats the results for regime F. The prior in table 2 over the fraction of rule-of-thumb agents, $\mu$, is centered at 0.30 and puts 90 -percent of the probability on fractions between 0.14 and 0.48 . The preference parameter for government spending, $\alpha_{G}$, obeys a uniform prior centered at 0 , and places equal probability on spending being a substitute or a complement, with the 90 -percent interval covering $[-1.58,1.58]$.

Rule-of-thumb models deliver much tighter prior distributions for multipliers in both policy regimes. In regime $\mathrm{M}$, when all fiscal instruments respond to stabilize debt (dashed lines, figure

\footnotetext{
${ }^{12}$ Galí et al. (2007) show that for with imperfectly competitive labor markets of the kind in the model of section 2 , when that fraction exceeds 0.25 , consumption multipliers are positive and output multipliers exceed unity on impact.
} 


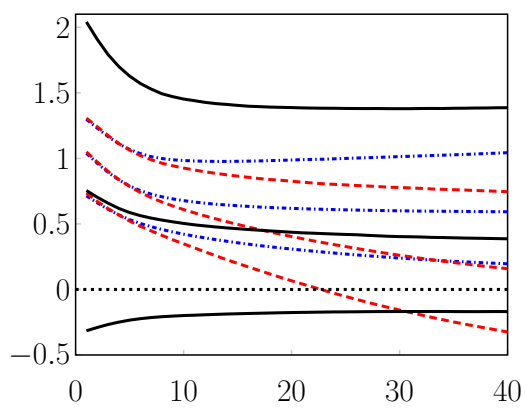

(a) Output Multiplier

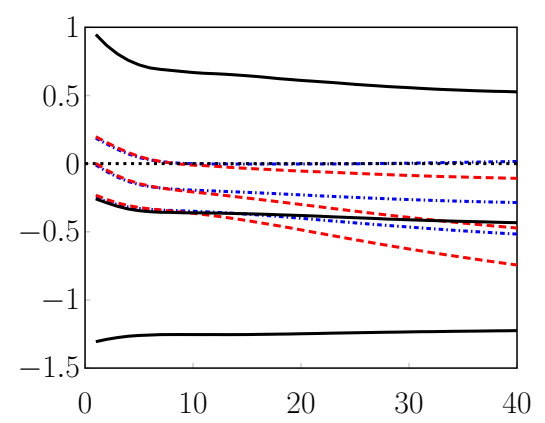

(b) Consumption Multiplier

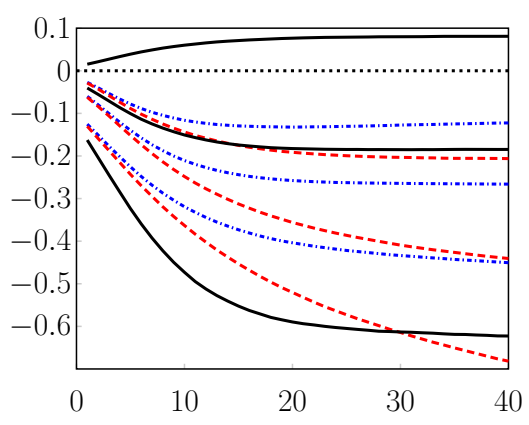

(c) Investment Multiplier

Figure 1: Present-value government spending multipliers in regime $\mathrm{M}$ for output, consumption and investment at various horizons with 90-percent probability bands. Government spending in utility unrestricted, steady-state taxes only, long debt (solid lines); rule-of-thumb agents, everything responds to debt, long debt (dashed lines); rule-of-thumb agents, steady-state taxes only, long debt (dotted-dashed lines).

1), output, consumption and investment multipliers are uniformly smaller than when there are steady-state tax distortions but only lump-sum transfers and government spending adjust to debt (dotted-dashed lines). Regardless of the fiscal adjustments, regime M rule-of-thumb models leave no possibility of positive investment multipliers.

A uniform prior over $\alpha_{G}$ permits both large positive and large negative consumption multipliers (solid lines), which rule-of-thumb agents preclude. Although most probability mass is on negative investment effects, this specification does offer some chance for small positive investment multipliers. Government spending in utility can also generate more persistence in multipliers.

Differences between the two specifications are less stark in regime F (figure 2). Although ruleof-thumb agents can produce large short- and long-run output multipliers, the range remains more tightly circumscribed than when government spending yields utility in an unrestricted manner. ${ }^{13}$ As the figure makes clear, government-spending-in-utility supports far wider ranges for all three multipliers, offering a more agnostic model with which to examine data.

This prior predictive analysis leads us to choose to take the government-spending-in-utility model to data, rather than the rule-of-thumb specification. Existing empirical work reports multipliers that vary substantially both in their magnitudes and in their persistence. A governmentspending-in-utility model, together with a uniform prior over $\alpha_{G}$, which is centered at 0 , can cover that reported range of multipliers, while it also admits the possibility of positive investment multipliers in either policy regime. Although a priori it is easy to list examples of government spending that either substitute for or complement private consumption, we do not have strong prior beliefs about whether in the aggregate the elasticity of substitution between government and private consumption is positive or negative. Our estimates will permit data to determine that elasticity.

\footnotetext{
${ }^{13} \mathrm{~A}$ uniform prior over $\mu$ ranging between $[0.2,0.5]$ raises output and consumption multipliers in the rule-of-thumb models at all horizons, but the differences from the figures are not large.
} 


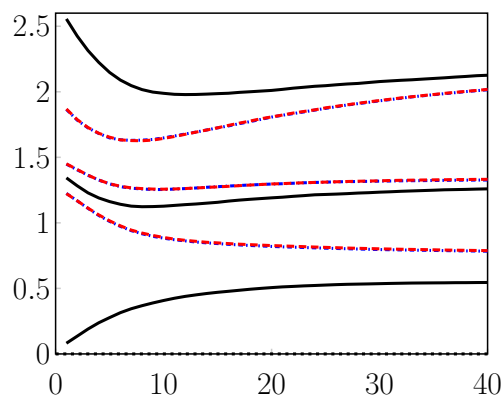

(a) Output Multiplier

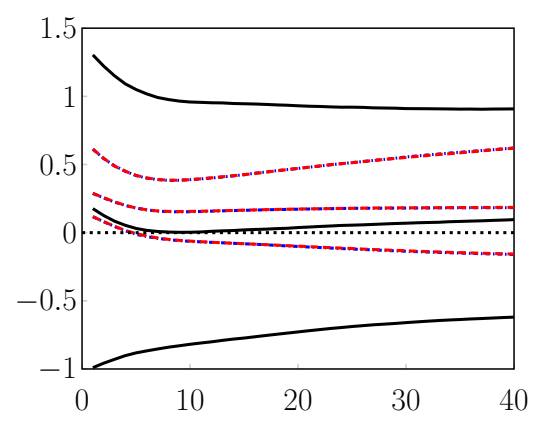

(b) Consumption Multiplier

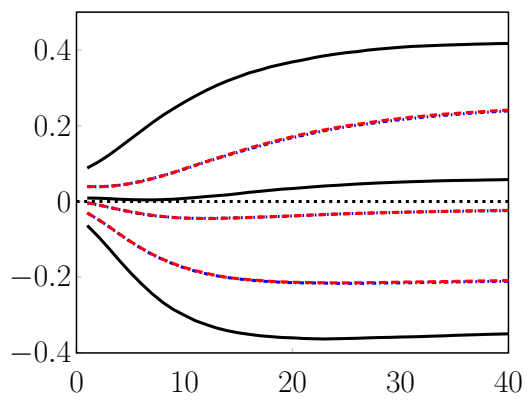

(c) Investment Multiplier

Figure 2: Present-value government spending multipliers in regime $\mathrm{F}$ for output, consumption and investment at various horizons with 90-percent probability bands. Government spending in utility unrestricted, steady-state taxes only, long debt (solid lines); rule-of-thumb agents, everything responds to debt, long debt (dashed lines); rule-of-thumb agents, steady-state taxes only, long debt (dotted-dashed lines).

\section{Data And Estimates}

We estimate a variant of model 4 from section 2 using quarterly U.S. data. There are eight observables: the log difference of aggregate consumption, investment, real wages, real government consumption, and the real market-value of government debt, log hours worked, the log difference of the GDP deflator, and the Federal Funds rate. Data are neither detrended nor demeaned. Details of the data construction and linkage to observables are given in the online appendix. The sample period is $1955 \mathrm{q} 1$ to $2014 \mathrm{q} 2$, but we also estimate over two sub-samples: the pre-Volcker era, 1955q1 to $1979 \mathrm{q} 4$ and the Great Moderation, 1982q1 to 2007q4. To further investigate the sensitivity of results to specific sub-samples, we conduct rolling window estimation. The first rolling window sample consists of 100 quarters from 1955q1 to 1979q4, and consecutively increases the start and end date by four quarters until the end of our data, with the last sample estimated from 1989q1 to $2013 q 4$.

Our dataset differs from the conventional ones used to estimate new Keynesian models [for example, Christiano et al. (2005) or Smets and Wouters (2007)] because it includes government debt and government consumption. Given the question at hand, these are natural additions, but they change the structure of the data in important ways. Fiscal data typically have more persistence than other macro aggregates, particularly the market value of government debt. By adding government debt, our data have more prominent lower frequency variation, so slightly larger than usual frictions are likely to improve the fit of the data.

\subsection{Methodology}

We use Bayesian methods to construct the parameters' posterior distribution, which is a combination of our priors and the likelihood function, calculated using the Kalman filter. The model eliminates rule-of-thumb agents and restricts $\mu=0$. We also do not include tax revenues or 
tax rates in the observables and restrict the model so that only public consumption and transfers potentially respond to debt. Tax distortions enter only the steady state, which restricts $\gamma_{K}=\gamma_{L}=\rho_{K}=\rho_{L}=0 .{ }^{14}$ The remaining parameters have either the priors listed in table 2 or the dogmatic priors discussed in section 3.2. As in the prior predictive with long debt, we assume a five-year duration for government bonds. We estimate subject to a monetary-fiscal regime prior. For regime $M$, we further restrict the parameters $\rho_{Z}$ and $\rho_{e z}$. Since transfers are nondistortionary in regime $\mathrm{M}, \rho_{Z}, \rho_{e z}$, and $\sigma_{Z}$ cannot be separately identified. We restrict $\rho_{Z}=0.98$ and $\rho_{e z}=0.8{ }^{15}$ Finally, the investment-specific, price and wage markup shocks are normalized to enter with a unit coefficient in the investment, price and wage inflation equations respectively.

We take 1.5 million draws from the posterior distribution using the random walk MetropolisHastings algorithm. For purposes of inference, we discard the first 500,000 draws and keep one every 50 draws to remove some correlation of the draws and obtain a sample from the posterior equal to our prior sample of $20,000 .^{16}$

\subsection{Posterior Estimates}

Table 5 reports the posterior estimates for the entire sample 1955q1-2014q2 for regimes M and F. The online appendix contains parameter estimates for other sub-periods. Three aspects of the estimates are critical for inferences. First, despite the diffuse priors, the credible sets indicate tight posteriors for nearly all parameters and across both regimes. Diffuse priors preserve agnosticism with respect to the multipliers. But data are sufficiently informative to push the posterior distributions into much tighter regions of the parameter space to deliver tightly estimated multipliers.

Second, the posterior means and credible sets are roughly in line with the values reported in the literature. Public and private consumption are estimated to be complements, as in Bouakez and Rebei (2007) and Fève et al. (2013). Parameters governing nominal rigidities are slightly larger than those in Smets and Wouters (2007), but consistent with values reported in Del Negro and Schorfheide (2008) and Herbst and Schorfheide (2014), who note that higher values in the wage and price stickiness parameters arise from more diffuse priors. Relatively high degrees of stickiness make the inflation and wage Phillips curves quite flat. Our estimates of habit formation are high, but they are within the 90th percentile bands of macro studies of external habits that Havranek, Rusnak, and Sokolova's (2015) meta study reports.

Finally, table 6 reports the log marginal data densities for both regimes, and for the entire

\footnotetext{
${ }^{14}$ We do not include tax rates as observables because quarterly measures of marginal tax rates are problematic. Jones's (2002) average labor tax rate is not marginal and it exhibits a trend in certain sub-samples. Effective tax rates calculated with alternative procedures, for instance Mendoza et al. (1994), give annual rates that require assumptions for interpolating quarterly values.

${ }^{15}$ In regime M, combinations of high (low) $\mathrm{AR}(1)$ coefficients and low (high) standard deviations are similar. The calibration for $\rho_{Z}$ and $\rho_{e z}$ was based on estimates from regime $\mathrm{F}$ and estimates in regime $\mathrm{M}$ with the high $\mathrm{AR}(1)$ coefficient and low standard deviation combination. Having AR(1) coefficients in both policy rules and policy shocks are essential in regime $\mathrm{F}$ to match features of the data.

${ }^{16}$ We set the step size to target an acceptance rate in the range of 20 to 40 percent across all cases. Diagnostics to determine chain convergence include cumulative sum of the draws (CUMSUM) statistics and Geweke's Separated Partial Means (GSPM) test. See the online appendix for more details.
} 
sample and subsamples. Log marginal data densities are calculated using Geweke's (1999) modified harmonic mean estimator with a truncation parameter of 0.5 . The data do not systematically prefer one regime over the other, so our analysis gives equal weight to the two regimes. ${ }^{17}$

\section{Multipliers}

Government spending multipliers are complex objects that depend on every aspect of a model's specification. Our estimates reveal some obvious aspects: the presence and degree of nominal and real rigidities; the role that government spending plays as a complement or substitute for private consumption; the stance of monetary and fiscal policies, which encompasses the sources of fiscal financing and the prevailing monetary-fiscal policy regime. But more subtle aspects of the model specification also emerge as important for determining multipliers: the absence or presence of steady-state distorting taxes; the level of steady-state government debt; and the maturity structure of outstanding debt. Both sets of aspects affect the transmission mechanism of government spending.

To understand the economic mechanisms that underlie our estimates of multipliers, we present results in several parts. We begin with an overview of similarities and differences in estimated responses to a government spending increase across the two policy regimes and then turn to discussions of the transmission mechanisms, first in regime $\mathrm{M}$, then in regime $\mathrm{F}$. Because differences in labor market behavior account for much of the variation in government spending effects in the two regimes, we discuss these differences in detail. Finally, fiscal financing of government spending differs markedly between regimes, so we end with an analysis of the sources of financing. In all results, government spending initially rises by 1 percent of steady-state government purchases, which is calibrated to be 11 percent of model GDP, in line with the average over the estimation period.

\subsection{Overview of Multipliers Across Policy Regimes}

Tables 7 and 8 summarize present-value multipliers for output, consumption and investment from the prior predictive and posterior estimates over three sample periods: the full sample, 1955q12014q2; the pre-Volcker period, 1955q1-1979q4; the post-Volcker pre-crisis period, 1982q1-2007q4. The tables report mean values and 90-percent credible sets for multipliers at selected horizons. Prior predictive analysis produces very wide ranges for possible multipliers, suggesting that a priori the model is agnostic about both the magnitudes and signs of government spending effects. Data are extremely informative about multipliers: posterior credible sets are substantially narrower than the prior sets and in many cases leave little ambiguity about government spending impacts.

Table 7 reports that in regime $\mathrm{M}$ posterior mean estimates of output multipliers are positive at all horizons and quite likely to be greater than 1 in the short run, but well below 1 over longer

\footnotetext{
${ }^{17}$ In contrast to Tan (2014) and Traum and Yang (2011), we find regime F is preferred by the data over some periods, particularly 1955q1-2014q2. This difference stems from elements of our model in regime $F$ that help the model match features of the data, such as the inclusion of long-term debt and steady-state tax rates. See section 5.3 for more discussion. Tan (2014) finds the minimal econometric approach, which elicits priors from a simpler new Keynesian model, can change regime rankings.
} 


\begin{tabular}{|c|c|c|c|c|}
\hline \multirow{3}{*}{ Parameter } & \multicolumn{4}{|c|}{ 1955q1:2014q2 } \\
\hline & \multicolumn{2}{|c|}{ Regime M } & \multicolumn{2}{|c|}{ Regime $\mathbf{F}$} \\
\hline & mean & $90 \%$ C.S. & mean & 90\% C.S. \\
\hline \multicolumn{5}{|l|}{ Preference and HHs } \\
\hline$\xi$, inverse Frisch labor elast. & 1.77 & {$[1.08,2.43]$} & 2.34 & {$[1.50,3.19]$} \\
\hline$\theta$, habit formation & 1.00 & {$[0.99,1.00]$} & 0.99 & {$[0.98,1.00]$} \\
\hline$\alpha_{G}, G$ in utility & -0.24 & {$[-0.41,-0.07]$} & -0.20 & {$[-0.38,-0.02]$} \\
\hline \multicolumn{5}{|l|}{ Frictions \& Production } \\
\hline $100 \gamma$, SS tech growth & 0.25 & {$[0.17,0.31]$} & 0.25 & {$[0.18,0.31]$} \\
\hline$\psi$, capital utilization & 0.16 & {$[0.10,0.23]$} & 0.15 & {$[0.08,0.23]$} \\
\hline$s$, inv adj cost & 5.46 & {$[3.78,7.15]$} & 4.80 & {$[3.20,6.37]$} \\
\hline$\omega_{p}$, price stickiness & 0.92 & {$[0.90,0.94]$} & 0.95 & {$[0.94,0.96]$} \\
\hline$\omega_{w}$, wage stickiness & 0.92 & {$[0.89,0.94]$} & 0.87 & {$[0.84,0.90]$} \\
\hline$\chi_{p}$, price indexation & 0.06 & {$[0.01,0.11]$} & 0.06 & {$[0.01,0.11]$} \\
\hline$\chi_{w}$, wage indexation & 0.18 & {$[0.11,0.26]$} & 0.18 & {$[0.10,0.25]$} \\
\hline \multicolumn{5}{|l|}{ Monetary Policy } \\
\hline$\phi_{\pi}$, interest rate resp. to inflation & 0.90 & {$[0.74,1.06]$} & 0.15 & {$[0.08,0.23]$} \\
\hline$\phi_{y}$, interest rate resp. to output & 0.10 & {$[0.08,0.12]$} & 0.14 & {$[0.12,0.17]$} \\
\hline$\rho_{r}$, lagged interest rate resp. & 0.71 & {$[0.64,0.78]$} & 0.15 & {$[0.07,0.23]$} \\
\hline \multicolumn{5}{|l|}{ Fiscal Policy } \\
\hline$\gamma_{G}$, govt cons. resp. to debt & 0.26 & {$[0.17,0.35]$} & 0.0000 & {$[-0.0016,0.0017]$} \\
\hline$\gamma_{Z}$, transfer resp. to debt & -0.11 & {$[-0.20,-0.02]$} & 0.0000 & {$[-0.0017,0.0017]$} \\
\hline$\rho_{G}$, lagged govt cons resp. & 0.98 & {$[0.98,0.99]$} & 0.99 & {$[0.98,0.99]$} \\
\hline$\rho_{Z}$, lagged transfer resp. & 0.98 & n.e. & 0.98 & {$[0.97,0.99]$} \\
\hline \multicolumn{5}{|l|}{ Shocks } \\
\hline$\rho_{a}$, technology & 0.23 & {$[0.12,0.35]$} & 0.27 & {$[0.16,0.39]$} \\
\hline$\rho_{b}$, preference & 0.40 & {$[0.30,0.50]$} & 0.39 & {$[0.29,0.49]$} \\
\hline$\rho_{\text {em }}$, monetary policy & 0.39 & {$[0.26,0.50]$} & 0.89 & {$[0.85,0.92]$} \\
\hline$\rho_{i}$, investment & 0.69 & {$[0.62,0.77]$} & 0.58 & {$[0.51,0.65]$} \\
\hline$\rho_{w}$, wage markup & 0.18 & {$[0.09,0.26]$} & 0.16 & {$[0.07,0.26]$} \\
\hline$\rho_{p}$, price markup & 0.74 & {$[0.67,0.82]$} & 0.75 & {$[0.68,0.82]$} \\
\hline$\rho_{\text {eg }}$, govt cons & 0.13 & {$[0.06,0.20]$} & 0.12 & {$[0.05,0.18]$} \\
\hline$\rho_{e z}$, transfers & 0.80 & n.e. & 0.96 & {$[0.94,0.98]$} \\
\hline $100 \sigma_{a}$, technology & 1.05 & {$[0.96,1.13]$} & 1.05 & {$[0.97,1.14]$} \\
\hline $100 \sigma_{b}$, preference & 81.61 & {$[43.09,116.15]$} & 52.03 & {$[22.68,76.43]$} \\
\hline $100 \sigma_{m}$, monetary policy & 0.22 & {$[0.20,0.23]$} & 0.22 & {$[0.20,0.24]$} \\
\hline $100 \sigma_{i}$, investment & 0.75 & {$[0.64,0.86]$} & 0.95 & {$[0.83,1.07]$} \\
\hline $100 \sigma_{w}$, wage markup & 0.35 & {$[0.30,0.39]$} & 0.34 & {$[0.30,0.39]$} \\
\hline $100 \sigma_{p}$, price markup & 0.09 & {$[0.07,0.10]$} & 0.07 & {$[0.06,0.09]$} \\
\hline $100 \sigma_{G}$, govt cons & 1.83 & {$[1.69,1.97]$} & 1.86 & {$[1.72,2.01]$} \\
\hline $100 \sigma_{Z}$, transfers & 3.22 & {$[2.30,4.09]$} & 0.50 & {$[0.34,0.67]$} \\
\hline $\bar{L}$, mean hours obs & 481.12 & {$[477.29,485.13]$} & 474.04 & {$[470.14,477.85]$} \\
\hline $\bar{\pi}$, mean inflation obs & 0.59 & {$[0.18,1.00]$} & 0.68 & {$[0.28,1.09]$} \\
\hline Inflation Phillips curve slope & 0.0071 & {$[0.0036,0.0104]$} & 0.0028 & {$[0.0016,0.0039]$} \\
\hline Wage Phillips curve slope & 0.0005 & {$[0.0002,0.0008]$} & 0.0013 & {$[0.0006,0.0019]$} \\
\hline
\end{tabular}

Table 5: Posterior distributions for estimated parameters: means and 90-percent credible sets. n.e. denotes not estimated

\begin{tabular}{c|ccc}
\hline \hline & \multicolumn{3}{|c}{ Log Marginal Data Density } \\
& $1955 \mathrm{q} 1$ & $1955 \mathrm{q} 1$ & $1982 \mathrm{q} 1$ \\
& $-2014 \mathrm{q} 2$ & $-1979 \mathrm{q} 4$ & $-2007 \mathrm{q} 4$ \\
\hline Regime M & -2557 & -1122 & -956 \\
Regime F & -2549 & -1125 & -968 \\
\hline \hline
\end{tabular}

Table 6: Log marginal data densities 
periods. These multipliers are larger over the full sample, which includes the 2008 crisis, than over either shorter sub-samples. ${ }^{18}$ This pattern carries over to consumption multipliers: positive in the short run and at all horizons over the full sample, but zero or even negative at longer horizons in the 1955-1979 and 1982-2007 sub-periods. Higher government spending unambiguously crowds out private investment in regime M: at all horizons and sub-periods, the 90-percent credible sets for investment multipliers are strongly negative even though the prior predictive places some probability on positive investment multipliers.

Output Multiplier: $P V \frac{\Delta Y}{\Delta G}$

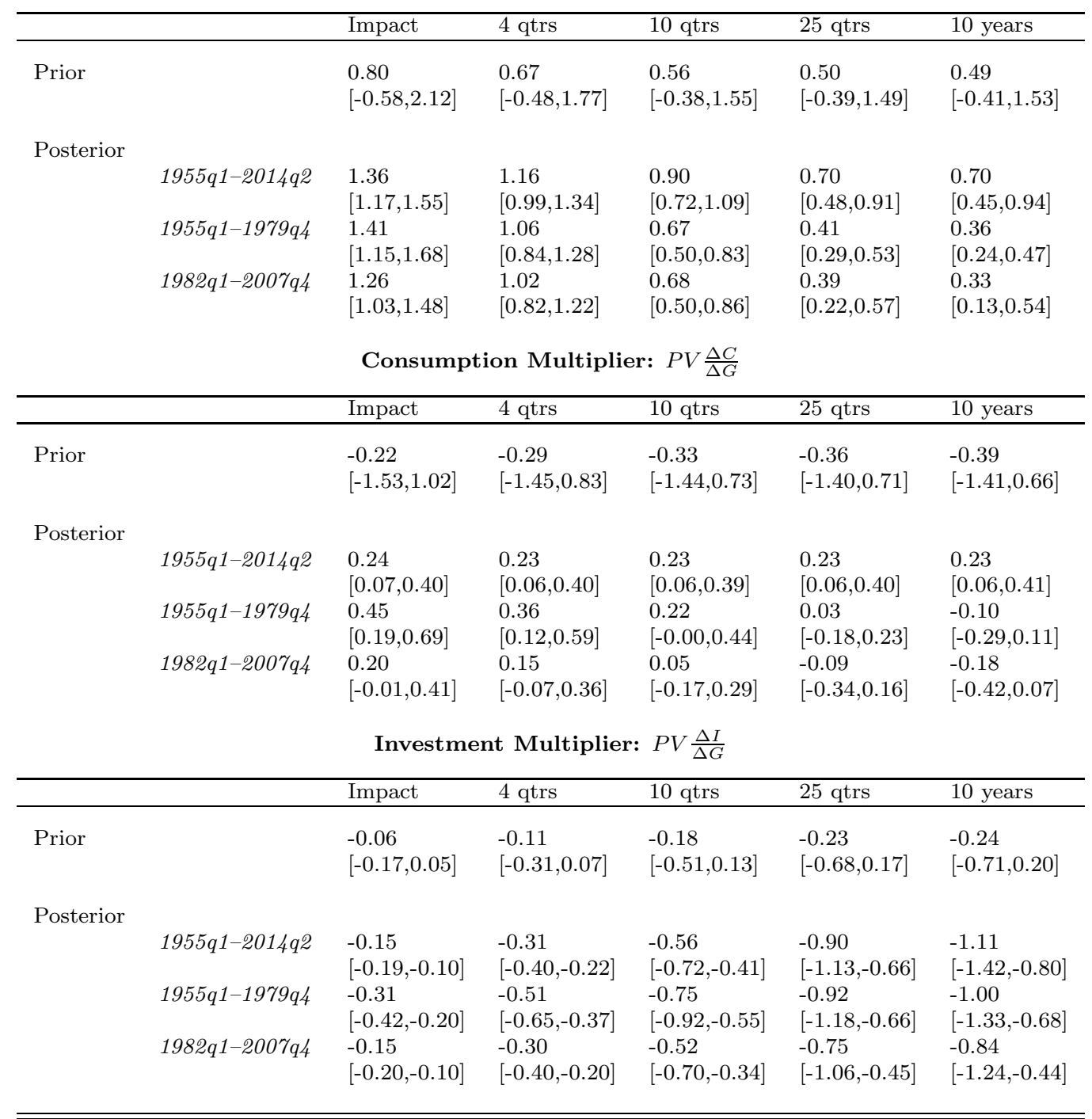

Table 7: Prior versus posterior mean multipliers for regime M. 90-percent credible sets in brackets.

Regime F multipliers appear in table 8. Unlike regime M, now the prior suggests that positive output multipliers are nearly certain over longer horizons. For the 1955-2014 sample period, mean

\footnotetext{
${ }^{18}$ Ramey (2011) reviews the theoretical and empirical literature and concludes that the output multiplier is between 0.8 and 1.5, in line with our impact estimates in both regimes.
} 
estimates of output multipliers are more than twice the size in regime M: at 10 years, the 90percent set in $\mathrm{F}$ is $[1.65,2.09]$, whereas it is $[0.45,0.94]$ in $\mathrm{M}$. Starker differences emerge in estimates from the two sub-periods, where the longer-run output multipliers are three to four times larger in F. Consumption multipliers over the three sample periods are comparable across the regimes, but marginally more likely to be positive in F. Investment impacts also display regime differences: whereas those multipliers are strongly negative in $\mathrm{M}$, there is significant probability mass on positive investment impacts in F, particularly at longer horizons.

Output Multiplier: $P V \frac{\Delta Y}{\Delta G}$

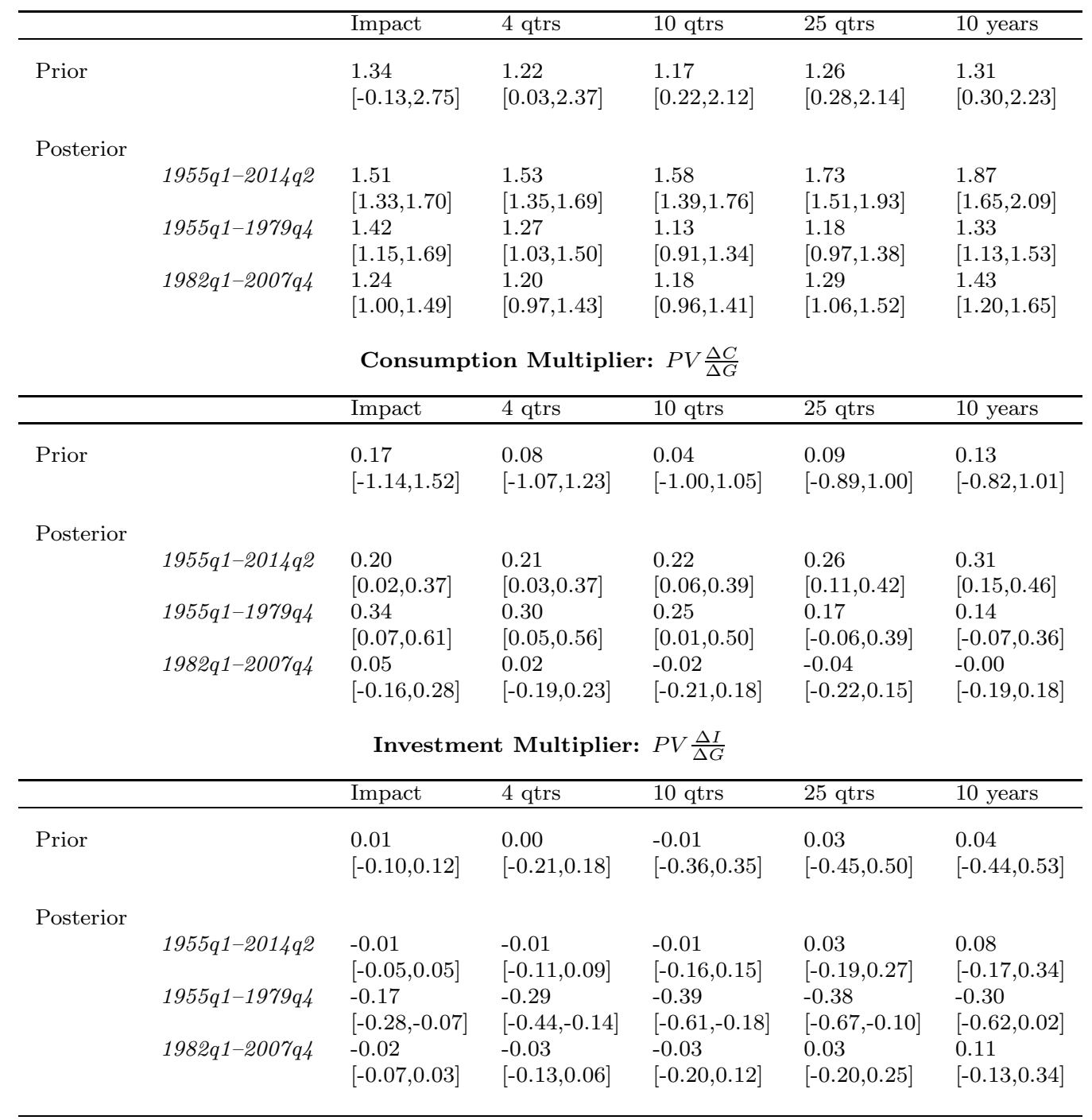

Table 8: Prior versus posterior mean multipliers for regime F. 90-percent credible sets in brackets.

Figure 3 displays the impacts - posterior means and 90-percent credible intervals - of an exogenous increase in government spending in both regimes, estimated from 1955q1 to 2014q2. Mean responses in regime $\mathrm{M}$ appear as dashed lines, while those in regime $\mathrm{F}$ are solid lines. Consumption multipliers in both regimes are positive and about 0.2 for the first four years, before rising to over 

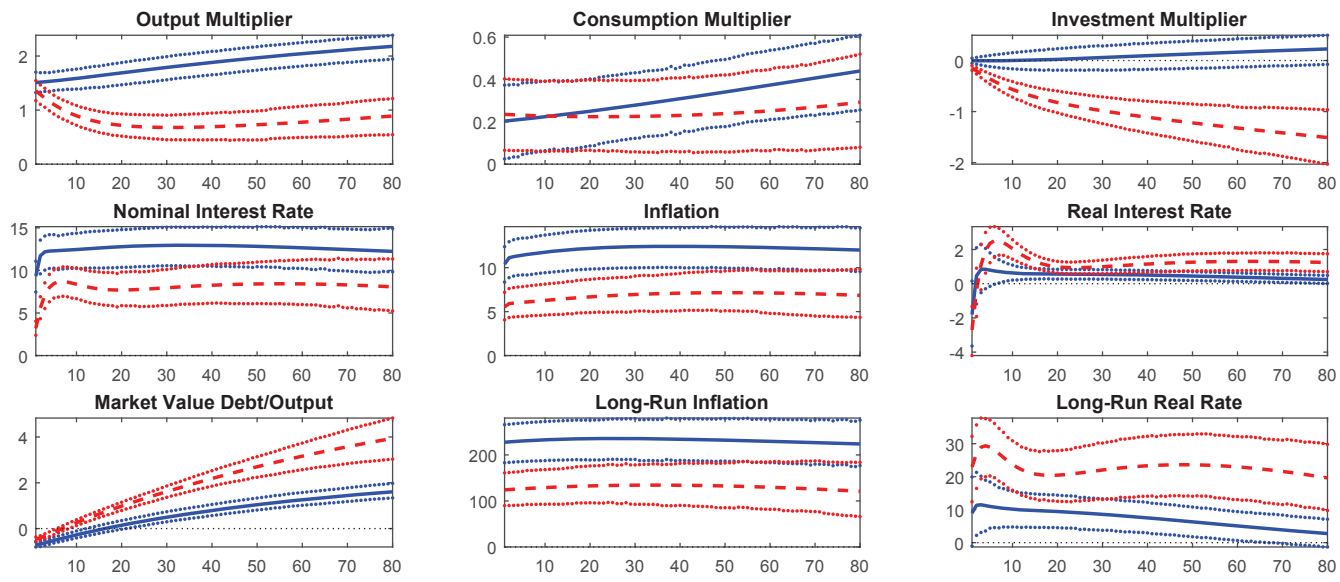

Long-Run Inflation

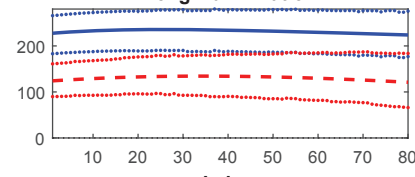

Long-Run Real Rate
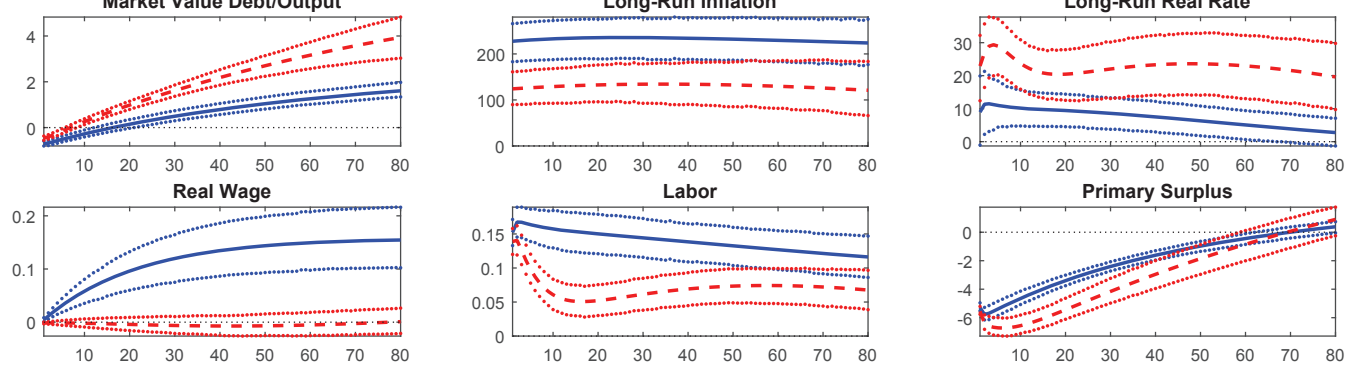

Figure 3: Responses over 80 quarters to a government spending increase in estimated regime M (dashed lines) and regime F (solid lines) over period 1955q1-2014q2. Responses displayed are for the posterior mean parameters and the 90 -percent impulse response credible intervals. Top panels are present value multipliers for output, consumption and investment, interest rates and inflation rates are converted to annualized basis points, and the remaining variables are in percentage deviations from steady state.

0.4 in $\mathrm{F}$ at longer horizons. ${ }^{19}$ Output and investment multipliers are substantially larger in regime $\mathrm{F}$ than in regime M. Average impact output multipliers are similar across regimes - 1.35 in $\mathrm{M}$ and 1.51 in F-but diverge over longer horizons: after 20 years, 0.9 in $\mathrm{M}$ and 2.1 in F. Stark differences appear in the effects of government spending on investment: in regime $\mathrm{M}$, investment is strongly crowded out, while in regime $\mathrm{F}$ investment rises modestly. At the end of the horizon in the figure, the present value of investment is $\$ 1.50$ lower in $\mathrm{M}$ and is 23 cents higher in $\mathrm{F}$.

In neither regime do higher multipliers arise from lower real interest rates, a finding that differs from existing literature. Monetary policy reduces the one-period real rate in regime $\mathrm{M}$ for only two periods and in regime $\mathrm{F}$ lower real rates occur only on impact. Long-run real interest rates, which are the relative prices that directly affect consumption decisions, are higher in both regimes, but about twice as high in $\mathrm{M}$ as in $\mathrm{F} .{ }^{20}$ Higher real rates are associated with both higher nominal rates and higher inflation rates, which rise more in regime $\mathrm{F}$ than in $\mathrm{M}$. In neither case, though, are these increases large - the mean inflation increase in M is about 6 basis points and 12 basis points in $\mathrm{F}$.

\footnotetext{
${ }^{19}$ These present-value multipliers do not mean that consumption is 40 cents higher after 20 years. They mean that if government spending rises in present value by $\$ 1$ over the 20 -year horizon, then the present value of consumption is 40 cents higher over that horizon.

${ }^{20}$ Long-run real rates are derived from combining the consumption Euler equation with the term structure relation to define the long-run real rate, $\hat{r}_{t}^{L}$, recursively as $\hat{r}_{t}^{L}=-\hat{P}_{t}^{B}-E_{t} \hat{\pi}_{t+1}+\left(\frac{\beta \rho}{e^{\gamma}}\right) E_{t}\left(\hat{r}_{t+1}^{L}+\hat{P}_{t+1}^{B}\right)$. Long-run inflation, $\hat{\pi}_{t}^{L}$, is defined as $\hat{\pi}_{t}^{L}=-\hat{r}_{t}^{L}-\hat{P}_{t}^{B}$. Because long-run real interest and inflation rates are discounted sums over the infinite future, they have a similar flavor to multipliers by reporting the discounted present value of rates.
} 


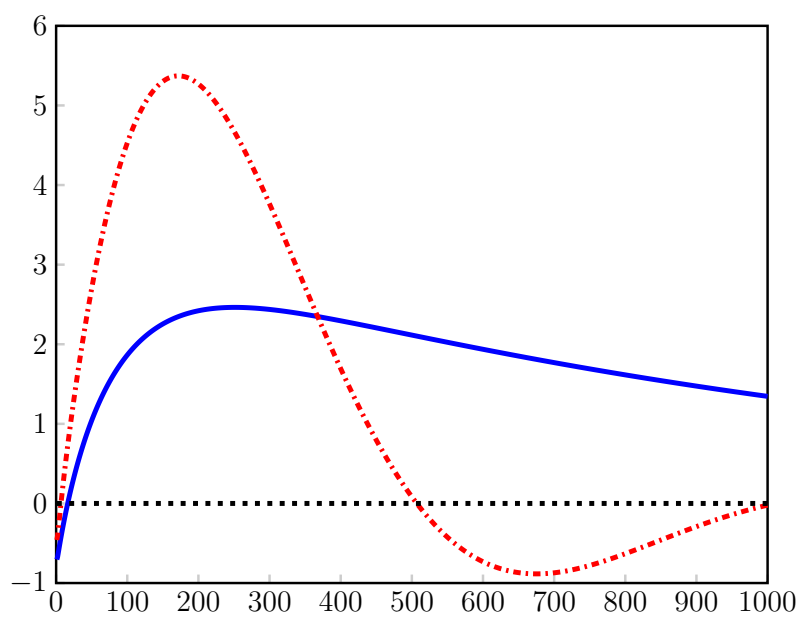

(a) Market Value of Debt / Output

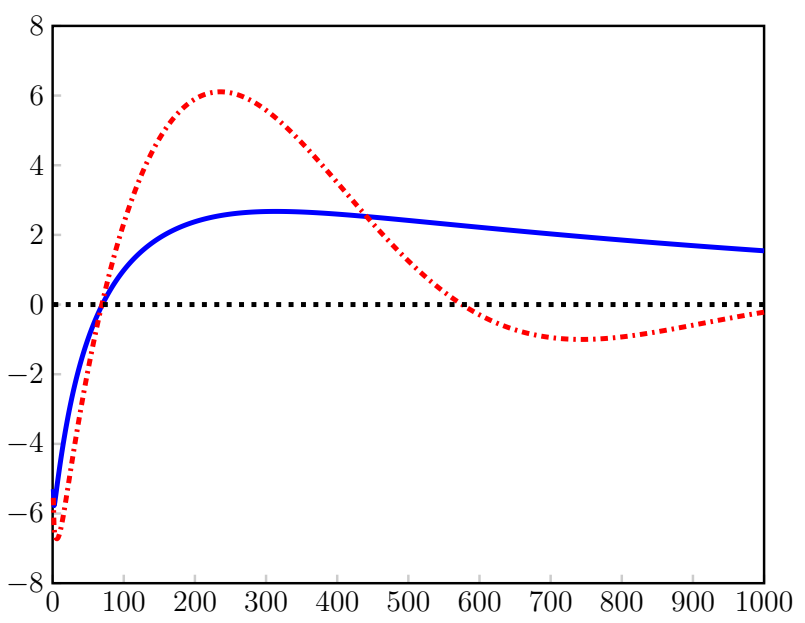

(b) Primary Surplus

Figure 4: Responses of debt and primary surplus to a government spending increase in estimated regime M (dashed lines) and regime F (solid lines) over period 1955q1-2014q2. Responses displayed are for the posterior mean parameters and variables are in percentage deviations from steady state.

Long-run inflation, however, does rise a fair amount in both regimes: a little under 1 percentage point in regime $\mathrm{M}$ and about 2.2 percentage points in $\mathrm{F}$.

Substantial differences across regimes appear in labor market responses. Real wages remain unchanged in regime $\mathrm{M}$, but rise strongly and persistently in $\mathrm{F}$. Although short-run increases in labor are similar in the two regimes, in regime $\mathrm{M}$ the increase is not sustained, while in $\mathrm{F}$ hours worked remain high over the 20-year period in the figure. These differences, which section 5.4 dissects, highlight how the transmission mechanisms vary across regimes.

In both regimes, the fiscal expansion initially lowers the market value of debt as a share of output because both output rises and bond prices fall. The very different sources of fiscal financing in the two regimes appear in figure 4, which reports fiscal responses over 1000 periods to reveal the model's low-frequency dynamics. The transition to the initial steady state is extremely slow, echoing Chung and Leeper's (2007) VAR evidence. In regime M estimates, fiscal policy raises transfers and reduces government purchases in response to higher debt, while in regime $\mathrm{F}$ those responses are muted. Both regimes have tax revenues rise passively with capital, labor and consumption increases. A critical difference in financing comes from the spending reversals that regime $\mathrm{M}$ triggers. These reversals raise surpluses and the value of debt more than in F, but then cause debt to overshoot the steady state to generate low-frequency oscillations around steady state. Oscillating government spending produces oscillations in other variables that are absent from regime $\mathrm{F}$, where long-run convergence to steady state is monotonic.

We now dig more deeply into the transmission mechanisms in the two regimes to better understand the crucial differences that appear in figure 3: multipliers are larger in regime $\mathrm{F}$ than in $\mathrm{M}$, especially over the long run; variables are substantially more persistent in $\mathrm{F}$ than in $\mathrm{M}$. 


\subsection{Transmission Mechanism in Regime M}

Regime M combines active monetary policy with passive fiscal policy. Estimates of fiscal behavior, however, differ somewhat from canonical new Keynesian models that assume lump-sum taxes are the passive instrument that stabilizes debt. In the 1955q1-2014q2 estimates, government spending is the stabilizing instrument: estimates have spending fall as the debt-output ratio rises, while lump-sum transfers move perversely and rise as debt rises. The estimated "spending reversals," in Corsetti, Meier and Müller's (2012) terminology, play a key role in regime M's transmission mechanism.

\subsubsection{Important Parameters To shed light on the transmission mechanisms that under-} lie the estimated multipliers, we calculate a measure of root mean square deviation (RMSD) for each parameter. For each draw of the posterior parameters, $\tilde{\theta}=\left[\begin{array}{lll}\tilde{\theta}_{1} & \ldots & \tilde{\theta}_{n}\end{array}\right]^{\prime}$ from the posterior distribution $p(\theta)$, we calculate multipliers $\tilde{\omega}(\tilde{\theta})$. Denote the new parameter vector by $\tilde{\theta}^{i}=\left[\begin{array}{lllll}\tilde{\theta}_{1} & \ldots & E\left[\theta_{i}\right] & \ldots & \tilde{\theta}_{n}\end{array}\right]^{\prime}$, where $E\left[\theta_{i}\right]$ fixes the $i^{t h}$ parameter at its posterior mean, and calculate the multipliers, $\tilde{\omega}^{i}\left(\tilde{\theta}^{i}\right)$. Repeat this for each $i=1,2, \ldots n$. The RMSD is the root mean square deviation between the two multipliers $\tilde{\omega}(\tilde{\theta})$ and $\tilde{\omega}^{i}\left(\tilde{\theta}^{i}\right)$ : it measures how much the multiplier varies on average due to parameter $i$. The RMSD is largest for the parameters that are most influential for the multiplier.

Table 9 displays the top five parameters by the RMSD ranking, as well as their total contribution to RMSD variation, across a range of estimated model specifications. The table displays results for output and consumption present-value multipliers on impact and after 25 quarters following a government spending shock. Most of the parameters that RMSD calculations identify as important for output and consumption multipliers fall into three categories: preferences $\left(\alpha_{G}\right.$, the coefficient on government consumption in utility; $\theta$, the degree of habit formation), nominal rigidities $\left(\omega_{p}\right.$, the Calvo parameter for price setting; $\omega_{w}$, the Calvo parameter for wage setting; $\chi_{p}$, the degree of inflation indexation), and policy parameters $\left(\phi_{\pi}\right.$ and $\phi_{y}$, the responses of monetary policy to inflation and output; $\gamma_{Z}$ and $\gamma_{G}$, the responses of transfers and government spending to debt in regime $\mathrm{M} ; \rho_{G}$ and $\rho_{e g}$, the persistence of the government spending shock).

5.2.2 Counterfactuals Based on the rankings in table 9, table 10 reports posterior means and 90-percent credible sets for impact and 25-quarter multipliers under a variety of counterfactual parameter settings in regime M. For comparison, the table also displays multipliers in the estimated model. For each counterfactual, we fix the parameters indicated in the table, and let the remaining parameters vary over the posterior. ${ }^{21}$

The persistently positive consumption multipliers in regime $\mathrm{M}$ that figure 3 depicts come from a combination of two estimated parameters: the complementarity of government spending $\left(\alpha_{G}<\right.$ 0 ) and strong external habit formation (large $\theta$ ). With complementarity, the initial increase in government spending raises private consumption despite higher real interest rates. Strong habits

\footnotetext{
${ }^{21}$ Results come from the same set of 20,000 draws in all cases. We discard draws that lead to indeterminacy.
} 
RMSD for Output on Impact

\begin{tabular}{llccccccc}
\hline Regime & Period & 1 & 2 & 3 & 4 & 5 & $\begin{array}{c}\text { Rof of } \\
\text { total }\end{array}$ \\
\hline $\mathrm{M}$ & & $1955 \mathrm{q} 1-2014 \mathrm{q} 2$ & $\alpha_{G}$ & $\phi_{\pi}$ & $\phi_{y}$ & $\gamma_{Z}$ & $\omega_{w}$ & 70.9 \\
$\mathrm{~F}$ & $1955 \mathrm{q} 1-2014 \mathrm{q} 2$ & $\alpha_{G}$ & $\omega_{p}$ & $\rho_{G}$ & $\phi_{y}$ & $\omega_{w}$ & 84.9 \\
$\mathrm{M}$ & $1955 \mathrm{q} 1-1979 \mathrm{q} 4$ & $\alpha_{G}$ & $\rho_{e g}$ & $\phi_{y}$ & $\rho_{G}$ & $s$ & 72.7 \\
$\mathrm{~F}$ & $1955 \mathrm{q} 1-1979 \mathrm{q} 4$ & $\alpha_{G}$ & $\omega_{p}$ & $\phi_{y}$ & $\rho_{e g}$ & $\rho_{G}$ & 73.1 \\
$\mathrm{M}$ & $1982 \mathrm{q} 1-2007 \mathrm{q} 4$ & $\alpha_{G}$ & $\psi$ & $\phi_{y}$ & $\rho_{e g}$ & $\phi_{\pi}$ & 76.1 \\
$\mathrm{~F}$ & $1982 \mathrm{q} 1-2007 \mathrm{q} 4$ & $\omega_{p}$ & $\alpha_{G}$ & $\chi_{p}$ & $\phi_{y}$ & $\rho_{G}$ & 80.4
\end{tabular}

RMSD for Consumption on Impact

\begin{tabular}{|c|c|c|c|c|c|c|c|}
\hline \multirow[t]{2}{*}{ Regime } & \multirow[t]{2}{*}{ Period } & \multicolumn{5}{|c|}{ Rank } & \multirow{2}{*}{$\begin{array}{l}\% \text { of } \\
\text { total }\end{array}$} \\
\hline & & 1 & 2 & 3 & 4 & 5 & \\
\hline M & $1955 \mathrm{q} 1-2014 \mathrm{q} 2$ & $\alpha_{G}$ & $\gamma_{Z}$ & $\theta$ & $\phi_{\pi}$ & $\gamma_{G}$ & 96.2 \\
\hline $\mathrm{F}$ & $1955 \mathrm{q} 1-2014 \mathrm{q} 2$ & $\alpha_{G}$ & $\omega_{p}$ & $\rho_{G}$ & $\phi_{y}$ & $\theta$ & 97.1 \\
\hline M & $1955 \mathrm{q} 1-1979 \mathrm{q} 4$ & $\alpha_{G}$ & $\theta$ & $\rho_{G}$ & $\rho_{e g}$ & $\gamma_{G}$ & 88.0 \\
\hline $\mathrm{F}$ & $1955 \mathrm{q} 1-1979 \mathrm{q} 4$ & $\alpha_{G}$ & $\theta$ & $\omega_{p}$ & $\phi_{y}$ & $\rho_{e g}$ & 92.8 \\
\hline M & $1982 q 1-2007 q 4$ & $\alpha_{G}$ & $\theta$ & $\rho_{G}$ & $\rho_{e g}$ & $\phi_{y}$ & 90.5 \\
\hline $\mathrm{F}$ & $1982 q 1-2007 q 4$ & $\alpha_{G}$ & $\omega_{p}$ & $\chi_{p}$ & $\theta$ & $\phi_{y}$ & 89.7 \\
\hline
\end{tabular}

RMSD for Output after 25 qtrs

\begin{tabular}{|c|c|c|c|c|c|c|c|}
\hline \multirow[t]{2}{*}{$\overline{\text { Regime }}$} & \multirow[t]{2}{*}{ Period } & \multicolumn{5}{|c|}{$\overline{\text { Rank }}$} & \multirow{2}{*}{$\begin{array}{l}\% \text { of } \\
\text { total }\end{array}$} \\
\hline & & 1 & 2 & 3 & 4 & 5 & \\
\hline M & $1955 q 1-2014 q 2$ & $\phi_{\pi}$ & $\gamma_{Z}$ & $\alpha_{G}$ & $\phi_{y}$ & $\gamma_{G}$ & 63.1 \\
\hline $\mathrm{F}$ & $1955 q 1-2014 q 2$ & $\omega_{p}$ & $\rho_{G}$ & $\phi_{y}$ & $\omega_{w}$ & $\phi_{\pi}$ & 80.6 \\
\hline M & $1955 q 1-1979 q 4$ & $\alpha_{G}$ & $\phi_{y}$ & $\phi_{\pi}$ & $\omega_{w}$ & $\rho_{G}$ & 53.0 \\
\hline $\mathrm{F}$ & $1955 q 1-1979 q 4$ & $\omega_{p}$ & $\phi_{y}$ & $\alpha_{G}$ & $\rho_{G}$ & $\phi_{\pi}$ & 67.6 \\
\hline M & $1982 q 1-2007 q 4$ & $\phi_{\pi}$ & $\rho_{G}$ & $\alpha_{G}$ & $\phi_{y}$ & $\omega_{p}$ & 62.4 \\
\hline $\mathrm{F}$ & $1982 q 1-2007 q 4$ & $\omega_{p}$ & $\chi_{p}$ & $\phi_{\pi}$ & $\phi_{y}$ & $\rho_{G}$ & 84.5 \\
\hline
\end{tabular}

RMSD for Consumption after 25 qtrs

\begin{tabular}{llcccccc}
\hline Regime & Period & \multicolumn{7}{c}{ Rank } & & $\begin{array}{c}\text { \% of } \\
\text { total }\end{array}$ \\
\hline $\mathrm{M}$ & 1 & 2 & 3 & 4 & 5 & ${ }^{2}$ \\
$\mathrm{~F}$ & $1955 \mathrm{q} 1-2014 \mathrm{q} 2$ & $\alpha_{G}$ & $\gamma_{Z}$ & $\phi_{\pi}$ & $\theta$ & $\gamma_{G}$ & 80.6 \\
$\mathrm{M}$ & $1955 \mathrm{q} 1-1979 \mathrm{q} 4$ & $\alpha_{G}$ & $\theta$ & $\rho_{G}$ & $\psi$ & $\gamma_{G}$ & 81.2 \\
$\mathrm{~F}$ & $1955 \mathrm{q} 1-1979 \mathrm{q} 4$ & $\alpha_{G}$ & $\theta$ & $\omega_{p}$ & $\psi$ & $\phi_{y}$ & 81.7 \\
$\mathrm{M}$ & $1982 \mathrm{q} 1-2007 \mathrm{q} 4$ & $\alpha_{G}$ & $\theta$ & $\rho_{G}$ & $\psi$ & $\phi_{\pi}$ & 80.3 \\
$\mathrm{~F}$ & $1982 \mathrm{q} 1-2007 \mathrm{q} 4$ & $\omega_{p}$ & $\chi_{p}$ & $\alpha_{G}$ & $\phi_{\pi}$ & $\phi_{y}$ & 85.1
\end{tabular}

Table 9: Root mean square deviations for estimated models. The five most influential parameters for multipliers according to the RMSD criterion that the text describes. Right column reports the total percentage contribution of those parameters to variation in the multiplier.

increase the desire for smooth consumption paths that rise only gradually over time, even as government spending decays back to steady state. Reducing habit formation, $\theta=0.8$, or removing government spending's complementarity to private consumption, $\alpha_{G}=0$, reduces output impacts and shifts the estimated consumption multipliers from positive to negative or zero. These preference parameters interact: it is the combination of the two counterfactuals that moves credible sets into negative territory for consumption and reduces the negative impacts on investment, confirming the source of persistent positive consumption impacts in the baseline estimates.

An increased capital utilization rate, $\psi=0.3$, weakens the increase in utilization. For effective capital to expand and boost production, the capital stock must decline less, tempering the strongly 
negative investment multipliers in the baseline estimates. Reducing nominal rigidities by setting $\omega_{p}=\omega_{w}=0.8$ and $\chi_{p}=\chi_{w}=0.25$ does not significantly alter the message of the estimates in regime M. Less rigid prices and wages soften real interest rate increases to raise consumption demand and output multipliers and attenuate the sharply negative investment multipliers. More hawkish monetary policy $\left(\phi_{\pi}=1.35\right)$ raises the real interest rate and reduces private demand and the output multiplier, while a less aggressive response to output $\left(\phi_{y}=0\right)$ raises output impacts and converts negative 25-quarter investment multipliers to zero.

The remaining counterfactuals that table 10 reports have minor effects on multipliers in regime M. Those counterfactuals include raising the speed at which transfers and spending adjust to stabilize debt $\left(\gamma_{Z}=\gamma_{G}=0.5\right)$, making all government debt one period $(\rho=0)$, and setting to zero steady-state tax rates as well as the response of transfers to debt $\left(\tau^{K}=\tau^{L}=\tau^{C}=\gamma_{Z}=0\right)$, which forces all fiscal adjustments to occur through future government spending changes. Among these, the more rapid fiscal financing $\left(\gamma_{Z}=\gamma_{G}=0.5\right)$ has the largest effect. In this case, lumpsum transfers are reduced to finance debt, creating negative wealth effects that make longer-run consumption multipliers less likely to be positive.

Counterfactuals in Regime $M$

\begin{tabular}{|c|c|c|c|c|c|c|c|}
\hline & & \multicolumn{3}{|c|}{ Posterior (Impact) } & \multicolumn{3}{|c|}{ Posterior (25 qtrs) } \\
\hline & & $P V \frac{\Delta Y}{\Delta G}$ & $P V \frac{\Delta C}{\Delta G}$ & $P V \frac{\Delta I}{\Delta G}$ & $P V \frac{\Delta Y}{\Delta G}$ & $P V \frac{\Delta C}{\Delta G}$ & $P V \frac{\Delta I}{\Delta G}$ \\
\hline & Estimated Model & $\begin{array}{c}1.36 \\
{[1.18,1.55]}\end{array}$ & $\begin{array}{c}0.24 \\
{[0.07,0.40]}\end{array}$ & $\begin{array}{c}-0.15 \\
{[-0.19,-0.10]}\end{array}$ & $\begin{array}{c}0.70 \\
{[0.48,0.91]}\end{array}$ & $\begin{array}{c}0.23 \\
{[0.06,0.40]}\end{array}$ & $\begin{array}{c}-0.90 \\
{[-1.14,-0.66]}\end{array}$ \\
\hline C1: & $\theta=0.8 \& \alpha_{G}=0$ & $\begin{array}{c}1.02 \\
{[0.96,1.08]}\end{array}$ & $\begin{array}{c}-0.10 \\
{[-0.13,-0.06]}\end{array}$ & $\begin{array}{c}-0.08 \\
{[-0.11,-0.06]}\end{array}$ & $\begin{array}{c}0.42 \\
{[0.26,0.57]}\end{array}$ & $\begin{array}{c}-0.29 \\
{[-0.42,-0.17]}\end{array}$ & $\begin{array}{c}-0.50 \\
{[-0.61,-0.38]}\end{array}$ \\
\hline & $A: \theta=0.8$ & $\begin{array}{c}1.26 \\
{[1.08,1.44]}\end{array}$ & $\begin{array}{c}0.12 \\
{[-0.04,0.27]}\end{array}$ & $\begin{array}{c}-0.11 \\
{[-0.14,-0.07]}\end{array}$ & $\begin{array}{c}0.52 \\
{[0.32,0.70]}\end{array}$ & $\begin{array}{c}-0.13 \\
{[-0.31,0.05]}\end{array}$ & $\begin{array}{c}-0.62 \\
{[-0.78,-0.45]}\end{array}$ \\
\hline & $B: \alpha_{G}=0$ & $\begin{array}{c}1.10 \\
{[1.05,1.15]}\end{array}$ & $\begin{array}{c}0.00 \\
{[-0.01,0.00]}\end{array}$ & $\begin{array}{c}-0.12 \\
{[-0.15,-0.08]}\end{array}$ & $\begin{array}{c}0.57 \\
{[0.40,0.75]}\end{array}$ & $\begin{array}{c}0.00 \\
{[-0.05,0.04]}\end{array}$ & $\begin{array}{c}-0.73 \\
{[-0.89,-0.57]}\end{array}$ \\
\hline $\mathrm{C} 2 \mathrm{:}$ & $\psi=0.3$ & $\begin{array}{c}1.34 \\
{[1.16,1.52]}\end{array}$ & $\begin{array}{c}0.23 \\
{[0.07,0.40]}\end{array}$ & $\begin{array}{c}-0.12 \\
{[-0.18,-0.08]}\end{array}$ & $\begin{array}{c}0.78 \\
{[0.54,1.03]}\end{array}$ & $\begin{array}{c}0.21 \\
{[0.04,0.37]}\end{array}$ & $\begin{array}{c}-0.73 \\
{[-0.98,-0.49]}\end{array}$ \\
\hline C3: & $\omega_{p}=\omega_{w}=0.8 \& \chi_{p}=\chi_{w}=0.25$ & $\begin{array}{c}1.60 \\
{[1.32,1.87]}\end{array}$ & $\begin{array}{c}0.24 \\
{[0.07,0.41]}\end{array}$ & $\begin{array}{c}0.04 \\
{[-0.13,0.18]}\end{array}$ & $\begin{array}{c}1.21 \\
{[0.50,1.86]}\end{array}$ & $\begin{array}{c}0.23 \\
{[0.06,0.39]}\end{array}$ & $\begin{array}{c}-0.34 \\
{[-0.99,0.27]}\end{array}$ \\
\hline C4a: & $\phi_{\pi}=1.35$ & $\begin{array}{c}1.27 \\
{[1.09,1.45]}\end{array}$ & $\begin{array}{c}0.23 \\
{[0.07,0.40]}\end{array}$ & $\begin{array}{c}-0.21 \\
{[-0.25,-0.17]}\end{array}$ & $\begin{array}{c}0.25 \\
{[0.13,0.36]}\end{array}$ & $\begin{array}{c}0.16 \\
{[0.00,0.34]}\end{array}$ & $\begin{array}{c}-1.27 \\
{[-1.49,-1.05]}\end{array}$ \\
\hline C4b: & $\phi_{y}=0.0$ & $\begin{array}{c}1.41 \\
{[1.21,1.60]}\end{array}$ & $\begin{array}{c}0.24 \\
{[0.07,0.41]}\end{array}$ & $\begin{array}{c}-0.11 \\
{[-0.14,-0.07]}\end{array}$ & $\begin{array}{c}1.56 \\
{[-0.08,3.10]}\end{array}$ & $\begin{array}{c}0.21 \\
{[-1.11,1.71]}\end{array}$ & $\begin{array}{c}0.03 \\
{[-0.07,0.16]}\end{array}$ \\
\hline C5: & $\gamma_{G}=\gamma_{Z}=0.5$ & $\begin{array}{c}1.31 \\
{[1.13,1.50]}\end{array}$ & $\begin{array}{c}0.23 \\
{[0.00,0.34]}\end{array}$ & $\begin{array}{c}-0.18 \\
{[-0.22,-0.14]}\end{array}$ & $\begin{array}{c}0.56 \\
{[0.44,0.69]}\end{array}$ & $\begin{array}{c}0.16 \\
{[-0.01,0.31]}\end{array}$ & $\begin{array}{c}-0.95 \\
{[-1.12,-0.78]}\end{array}$ \\
\hline C6: & $\rho=0$ & $\begin{array}{c}1.37 \\
{[1.18,1.55]}\end{array}$ & $\begin{array}{c}0.24 \\
{[0.07,0.40]}\end{array}$ & $\begin{array}{c}-0.14 \\
{[-0.19,-0.09]}\end{array}$ & $\begin{array}{c}0.72 \\
{[0.49,0.96]}\end{array}$ & $\begin{array}{c}0.24 \\
{[0.07,0.41]}\end{array}$ & $\begin{array}{c}-0.91 \\
{[-1.15,-0.65]}\end{array}$ \\
\hline C7: & $\tau^{K}=\tau^{L}=\tau^{C}=0, \gamma_{Z}=0$ & $\begin{array}{c}1.41 \\
{[1.22,1.61]}\end{array}$ & $\begin{array}{c}0.23 \\
{[0.06,0.40]}\end{array}$ & $\begin{array}{c}-0.18 \\
{[-0.24,-0.14]}\end{array}$ & $\begin{array}{c}0.60 \\
{[0.42,0.77]}\end{array}$ & $\begin{array}{c}0.21 \\
{[0.05,0.39]}\end{array}$ & $\begin{array}{c}-1.04 \\
{[-1.25,-0.82]}\end{array}$ \\
\hline
\end{tabular}

Table 10: Counterfactual multipliers for regime M estimated over 1955q1-2014q2. Posterior means and 90-percent credible intervals (in brackets).

Broader consequences of three counterfactuals appear in the posterior mean responses in figure 5 . 
Baseline estimates (solid lines) and three sets of counterfactuals appear in the figure. Intervening on preferences to eliminate government spending's estimated complementarity to consumption and to reduce the intensity of habits, converts the baseline positive consumption multipliers into strongly negative multipliers over the full 20-year horizon (dashed lines). This also reduces the output multiplier and, by crowding out investment less, softens the decline in investment. Strong habits and complementary of government spending are essential to deliver the sustained positive consumption multipliers in the baseline estimates.

More aggressive monetary policy raises nominal and real interest rates after the fiscal expansion, tempering the increase in inflation for several years (dotted-dashed lines). Sharply higher real rates reduce consumption multipliers relative to baseline estimates and dramatically lower investment. A reduced capital stock, together with substantially lower wages and short-lived labor increases, drive the present-value output multiplier to near zero at longer horizons.

The last counterfactual makes regime M Ricardian in the sense that only non-distorting transfers respond to debt; spending reversals that arise through the rule for government purchases are eliminated (dotted lines). ${ }^{22}$ Ricardian fiscal financing coincides with analyses in Christiano et al. (2011) and Cogan et al. (2010) and other multiplier studies. It produces smaller output multipliers than the estimated baseline, with consumption multipliers that turn negative after 10 years. These effects stem from somewhat higher real interest rates and much lower wages.

\subsection{Transmission Mechanism in Regime F}

Regime F couples passive monetary policy with active fiscal policy, a policy mix that breaks Ricardian equivalence. Debt-financed government spending does not trigger expectations of sufficiently high surpluses to stabilize debt. Instead, changes in bond prices and the price level ensure that the market value of debt is aligned with the expected present value of surpluses. Unlike simple expositions of this policy regime, the estimated model includes constant tax rates levied against capital and labor income and consumption, so a fiscal expansion does generate expectations of somewhat higher surpluses; those surpluses, though, are not a marginal source of financing and cannot stabilize debt.

5.3.1 Important Parameters Table 9 reports the five most important parameters for output and consumption multipliers in regime F. Important parameters include price and wage stickiness $\left(\omega_{p}\right.$ and $\left.\omega_{w}\right)$, preferences over government spending and habits $\left(\alpha_{G}\right.$ and $\left.\theta\right)$, monetary policy reactions to inflation and output $\left(\phi_{\pi}\right.$ and $\left.\phi_{y}\right)$, and the persistence of government spending $\left(\rho_{G}\right)$.

These RMSD results guide the counterfactual experiments that follow. Missing from the RMSD analysis is whether changes in steady-state variables matter for multipliers. As table 10's C6 and C7 counterfactuals suggest, steady-state changes in average maturity or tax rates have only tiny effects in regime $\mathrm{M}$. This is not the case in regime $\mathrm{F}$, as section 5.3 .2 discusses.

\footnotetext{
22 "Ricardian" refers only to the sources of financing that respond to the state of government debt. Some revenue is raised through (constant) steady-state tax rates on capital, labor and consumption.
} 

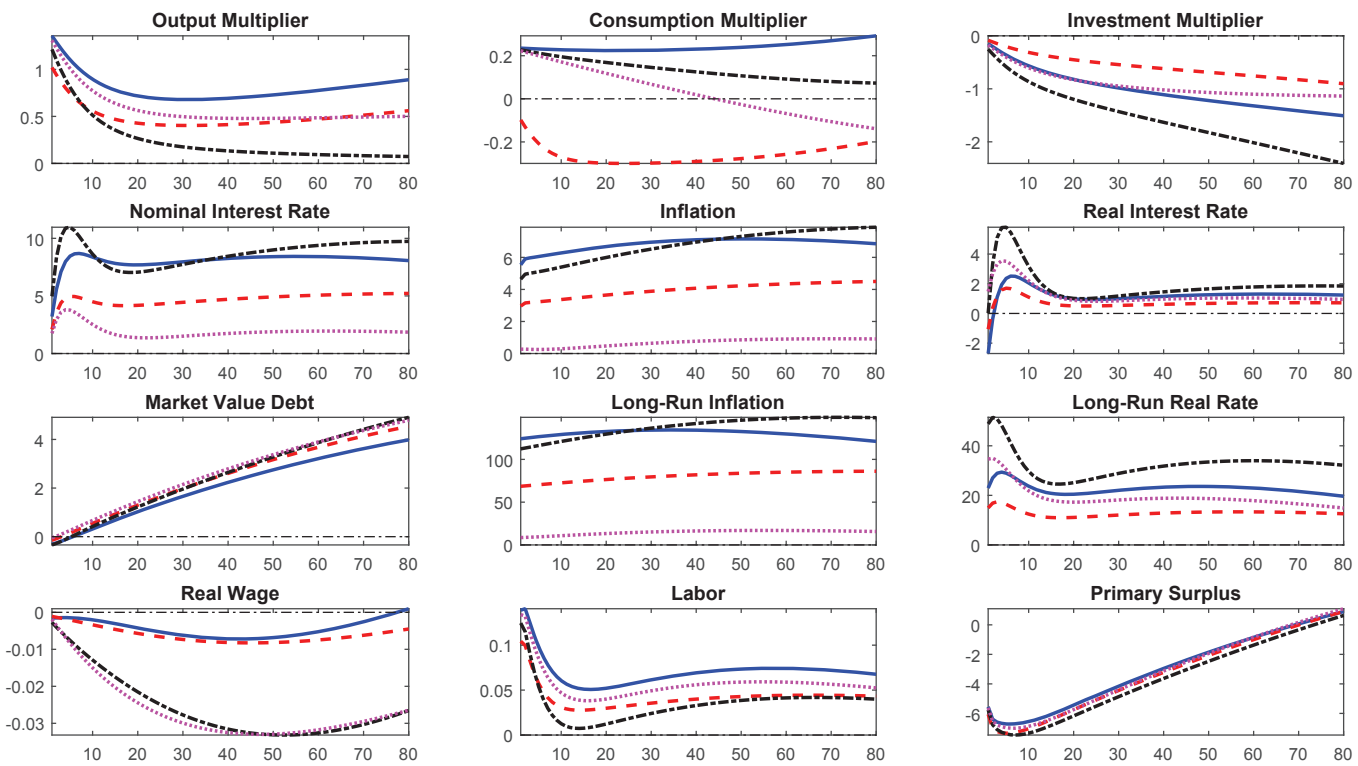

Figure 5: Counterfactual posterior mean responses to a government spending increase in estimated regime M, 1955q1-2014q2. Baseline estimates (solid lines); lower habits, $\theta=0.8$ and no government spending in utility, $\alpha_{G}=0$ (dashed lines); more aggressive monetary policy, $\phi_{\pi}=1.35$ and $\phi_{y}=0.2$ (dotted-dashed lines); Ricardian model, $\gamma_{G}=0, \gamma_{Z}=0.2$ (dotted lines). Top panels are present value multipliers for output, consumption and investment, interest rates and inflation rates are converted to annualized basis points, and the remaining variables are in percentage deviations from steady state. 
Counterfactuals in Regime F

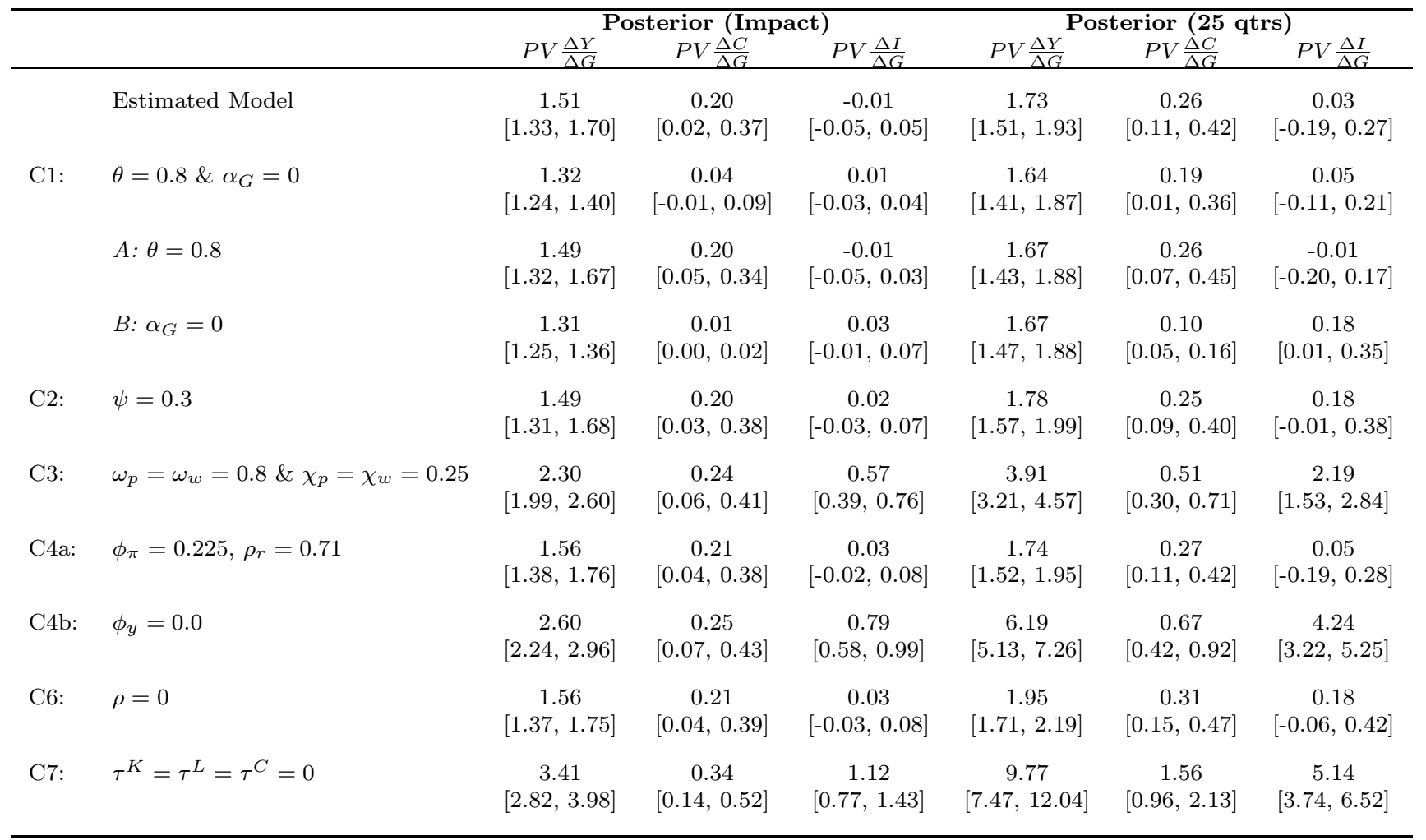

Table 11: Counterfactual multipliers for Regime F estimated over 1955q1-2014q2. Posterior means and 90-percent credible intervals (in brackets).

5.3.2 Counterfactuals Table 11 repeats for regime F many of the counterfactuals conducted in table 10 for regime M. Reducing habit intensity $(\theta=0.8)$ and removing government spending's complementarity $\left(\alpha_{G}=0\right)$ have much less effect on consumption multipliers in $\mathrm{F}$ than in regime $\mathrm{M}$. The impact multiplier falls from 0.2 to zero, but the 25 -quarter multiplier continues to be positive. Merely setting $\alpha_{G}=0$ still reduces the impact consumption multiplier, but it raises the longer-term investment multiplier from essentially zero to 0.18 .

Multipliers are uniformly higher when prices and wages are more flexible, an outcome that is no mystery in regime F. Less stickiness permits inflation to rise more after the increase in government spending which, when monetary policy is passive, reduces real interest rates in the short run. ${ }^{23}$ Lower real rates raise consumption and investment demand at the same time that they raise supply of labor.

Monetary policy's reaction to output, $\phi_{y}$, becomes quite powerful when nominal rigidities are strong, as in the baseline estimates. Making monetary policy unresponsive to output $\left(\phi_{y}=0\right)$ raises impact multipliers for output and investment, but the largest effects occur at longer horizons: the output multiplier exceeds six and the investment multiplier is over four at 25 quarters.

Very large multipliers arise when steady-state tax rates are zero. Impact multipliers for output

\footnotetext{
${ }^{23} \mathrm{~A}$ similar mechanism is in play when monetary policy confronts the zero lower bound [Christiano et al. (2011)].
} 
and investment rise substantially, but the biggest increases appear in longer-run multipliers, which are several times larger than in baseline estimates. Eliminating steady-state taxes as a source of revenue produces very large wealth effects in regime F: now an expansion in debt is completely unbacked by changes in future surpluses, sharply increasing demand now and in the future. ${ }^{24}$

Figure 6 reports dynamic impacts of a public spending expansion on the baseline posterior mean estimates (solid lines) and three counterfactuals. Reducing nominal rigidities (dashed lines) makes the real interest rate the dominant force in the transmission mechanism because inflation, which rises dramatically on impact, is transformed into sharply lower real rates by the passive monetary policy in regime $\mathrm{F}$ (dashed lines). Lower real rates trigger the typical reactions: households raise consumption and investment demand, firms with sticky prices increase labor demand to satisfy production, increasing equilibrium labor. All three multiplier measures are significantly higher than in the baseline estimates.

Enhanced price and wage flexibility raises the slopes of the inflation and wage Phillips curves to transmit increased real activity into still higher inflation and wages, with larger adjustments in both variables in the short run. Bond prices drop precipitously and drive the market value of debt-output ratio below steady state over the 20-year horizon in the figure. These large initial impacts are more fleeting because diminished stickiness reduces persistence in many responses, most notably nominal interest rates, inflation and labor-market variables.

Dramatic effects come from intervening on preference parameters to reduce habit intensity and eliminate government spending's complementarity, while also reducing the persistence of government spending (dotted-dashed lines). Without complementarity, the short-run consumption multiplier can turn negative as real interest rates rise modestly, while weaker habits permit long-run consumption multipliers to rise to the baseline's levels, even as the government spending injection dissipates. Output and investment multipliers also fall below their baseline levels. With a less sustained increase in demand due to reduced serial correlation in government purchases, labor and wages rise only tepidly.

The third counterfactual combines the first two to show that complementarity of government and private consumption and extremely persistent government spending - all of which emerge from the baseline estimates - are not necessary to generate persistently positive consumption multipliers in regime F (dotted lines). This scenario generates small, transitory increases in inflation, nominal interest rates and labor, yet a set of multipliers that is larger than in the baseline.

Persistence in regime $\mathrm{F}$ - in contrast to regime $\mathrm{M}$ - comes in large part from slowly evolving government debt. Analytical models of the two regimes make clear that government debt is an important state variable in $\mathrm{F}$, but disappears in equilibrium in purely Ricardian versions of $\mathrm{M}$. This role of debt is difficult to glean from the counterfactuals in figure 6, so we now turn to interventions on features of the steady state that have a direct bearing on the state of government debt.

\footnotetext{
${ }^{24}$ This counterfactual brings the model closest to the canonical fiscal theory setting with exogenous primary surpluses, which Dupor and Li (2015) study.
} 

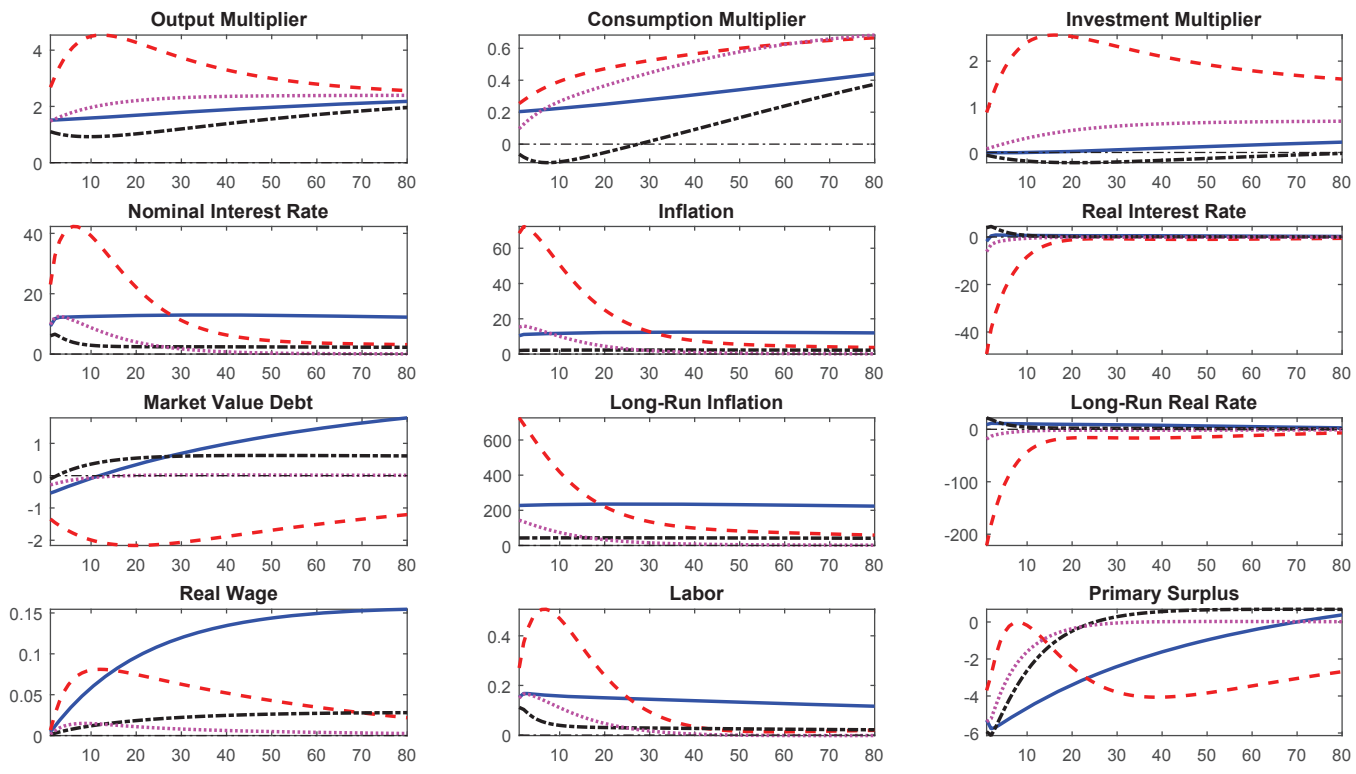

Figure 6: Counterfactual posterior mean responses to a government spending increase in estimated Regime F, 1955q1-2014q2. Baseline estimates (solid lines); lower nominal rigidities, $\omega_{p}=\omega_{w}=0.7$ (dashed lines); lower habits, $\theta=0.8$, no government spending in utility, $\alpha_{G}=0$, and less persistent spending shock, $\rho_{G}=0.9$ (dotted-dashed lines); lower nominal rigidities, $\omega_{p}=\omega_{w}=0.7$, lower habits, $\theta=0.8$, no government spending in utility, $\alpha_{G}=0$, and less persistent spending shock, $\rho_{G}=0.9$ (dotted lines). Top panels are present value multipliers for output, consumption and investment, interest rates and inflation rates are converted to annualized basis points, and the remaining variables are in percentage deviations from steady state. 
Figure 7 reports the baseline responses (solid lines) and responses from interventions on three aspects of the steady state that directly impact government debt. As tables 10 and 11 show, making all debt only one period or eliminating steady-state taxes on capital, labor and consumption has trivial effects on regime $\mathrm{M}$ multipliers, but substantial impacts on regime $\mathrm{F}$ multipliers. Eliminating longer-term debt by setting $\rho=0$ prevents bond prices from absorbing the higher government spending and brings more inflation into the present (dashed lines). One-period inflation rates are a bit higher than baseline, but long-term inflation and higher long-term real interest rates all but disappear. Because all debt revaluations must occur through contemporaneous inflation, the market value of debt is uniformly higher, increasing wealth effects from higher spending and shifting up demand for consumption. This higher demand induces firms to demand more labor and produce more goods, driving up wages.

Raising the steady-state debt-output ratio from the baseline of 36.8 percent to 150 percent reduces all the multipliers (dotted-dashed lines), an outcome that at first blush might seem counterintuitive. But a larger stock of debt presents a larger "nominal tax base" against which surprise inflation and bond prices operate. With more nominal debt outstanding, the market value of debt can adjust to a given reduction in the present value of surpluses with a smaller decline in bond prices and a smaller jump in inflation. Bond prices fall and inflation rises by less than in the baseline estimates. ${ }^{25}$ One-period and long-term real interest rates rise throughout the horizon in the figure to dampen demand, wages and employment. Mean investment multipliers shift from being mildly positive to mildly negative.

Table 11 shows that eliminating steady-state tax rates significantly raises multipliers. Figure 7 reduces capital, labor and consumption tax rates by 40 percent (dotted lines). All else equal, lower steady-state tax rates reduce expected future endogenous revenues, raise wealth, and increase consumption demand, labor demand, hours worked and output, all of which would increase multipliers dramatically. But more robust economic activity increases the tax bases against which the tax rates apply to generate revenue that partially offsets the lower tax rates and weaken wealth effects and demand. This attenuates but does not eliminate the boost to multipliers.

\subsection{Labor Market Behavior in the Two Regimes}

Both the baseline estimates in figure 3 and the counterfactuals make clear that an essential difference in the transmission of government spending in the two policy regimes stems from labor market behavior: labor responses are more persistent in $\mathrm{F}$, and real wages rise sharply in regime $\mathrm{F}$ but remain flat in M. We now explore that aspect of the transmission mechanism in detail.

In the baseline model with wages that are both sticky and indexed to past wages, the real wage

\footnotetext{
${ }^{25}$ Additional evidence that revaluation through bond prices is crucial comes from noticing that if all debt is one period $(\rho=0)$, then higher steady-state debt is irrelevant for inflation, interest rates and real economic activity.
} 


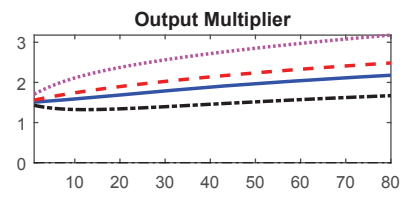

Nominal Interest Rate

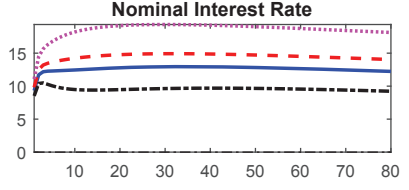

Market Value Debt

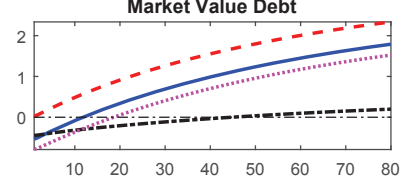

Real Wage

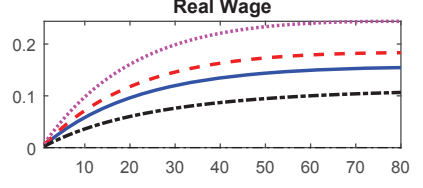

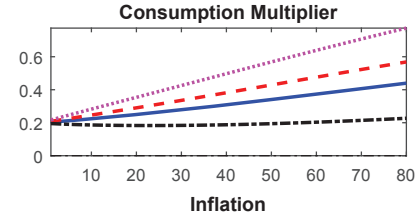

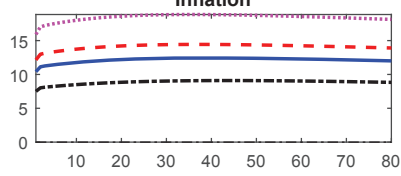

Long-Run Inflation

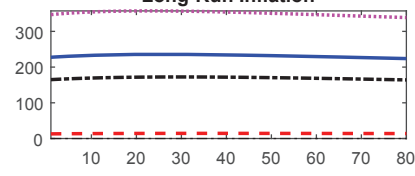

Labor

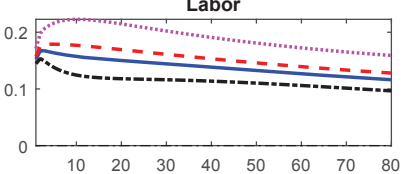

Investment Multiplier

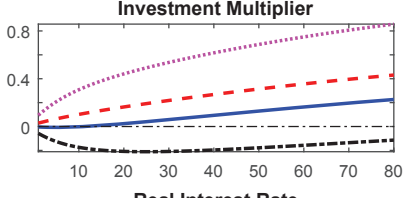

Real Interest Rate

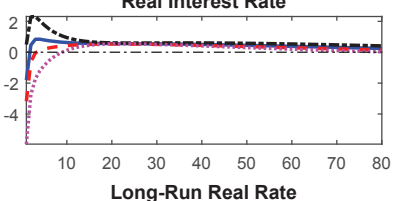

Long-Run Real Rate

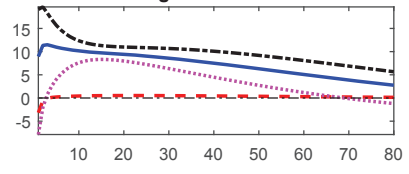

Primary Surplus

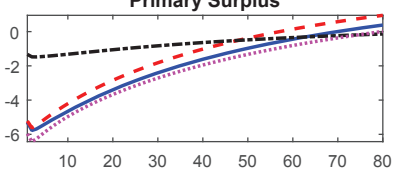

Figure 7: Counterfactual posterior mean responses to a government spending increase in estimated Regime F, 1955q1-2014q2. Baseline estimates (solid lines); only one-period debt, $\rho=0$ (dashed lines); higher steady state debt-GDP ratio, $s^{b}=150$ percent (dotted-dashed lines); steady-state tax rates reduced by 40 percent (dotted lines). Top panels are present value multipliers for output, consumption and investment, interest rates and inflation rates are converted to annualized basis points, and the remaining variables are in percentage deviations from steady state.

satisfies $^{26}$

$$
\begin{aligned}
\hat{w}_{t}= & \frac{1}{1+\beta} \hat{w}_{t-1}+\frac{\beta}{1+\beta} E_{t} \hat{w}_{t+1}-\kappa_{w} \hat{\varpi}_{t}+\frac{\chi_{w}}{1+\beta} \hat{\pi}_{t-1} \\
& -\frac{1+\beta \chi_{w}}{1+\beta} \hat{\pi}_{t}+\frac{\beta}{1+\beta} E_{t} \hat{\pi}_{t+1}+\frac{\chi_{w}}{1+\beta} \hat{u}_{t-1}^{a}-\frac{1+\beta \chi_{w}-\rho_{a} \beta}{1+\beta} \hat{u}_{t}^{a}
\end{aligned}
$$

where $\hat{\varpi}_{t}$ denotes deviations of the economy's average wage markup, defined as

$$
\hat{\varpi}_{t} \equiv \hat{w}_{t}-\left[\xi \hat{L}_{t}+\hat{u}_{t}^{b}-\hat{\lambda}_{t}\right]+\kappa_{w}^{-1} \hat{u}_{t}^{w}
$$

$\hat{\lambda}_{t}$ denotes the marginal utility of wealth, $\hat{L}_{t}$ is labor, $\hat{u}_{t}^{b}$ is the preference shock and $\hat{u}_{t}^{w}$ is the wage markup shock. ${ }^{27}$ When shocks to the economy cause the wage markup to be below its desired level, households increase their nominal wages. With sticky prices, this can raise the real wage, as equation (4) suggests. When nominal wages are flexible $-\omega_{w}=0$ - the wage markup is constant, $\hat{\varpi}_{t}=0$, and the real wage equals the marginal rate of substitution between consumption and leisure, given by the terms in brackets in equation (5). ${ }^{28}$ In this case, sticky prices can produce

\footnotetext{
${ }^{26}$ The Calvo parameter that determines wage stickiness, $\omega_{w}$, is embedded in $\kappa_{w} \equiv\left[\left(1-\beta \omega_{w}\right)(1-\right.$ $\left.\left.\omega_{w}\right)\right] /\left[\omega_{w}(1+\beta)\left(1+\frac{\left(1+\eta^{w}\right) \xi}{\eta^{w}}\right)\right]$.

${ }^{27}$ See the online appendix for derivations of these expressions.

${ }^{28}$ Under flexible prices, this yields the standard RBC model's labor demand equation, modified to include government spending in the utility function. Further restricting $\alpha_{G}=0$ delivers the familiar form: $\hat{w}_{t}=$
} 
higher real wages after government demand rises: some firms hire more labor to raise production, which drives up real wages. ${ }^{29}$ When nominal wages are sticky, labor supply is forced to adjust more to increases in labor demand.

Figure 8 explores the wage mechanisms triggered by higher government spending by using several counterfactual experiments in regimes $\mathrm{M}$ and F. For comparability across the policy specifications, we calibrate both models to the posterior mean estimates from regime $\mathrm{F}$ estimates over 1955q1-2014q2 (blue solid lines). To produce regime M, we use this calibration but replace $\phi_{\pi}$ and $\gamma_{G}$ with their posterior mean estimates in $\mathrm{M}\left(\phi_{\pi}=0.90\right.$ and $\left.\gamma_{G}=0.26\right)$, so differences across rows in the figure stem from distinct policy behavior. To this reference case that employs parameters estimated in regime F (solid lines), we add two counterfactuals: lower habit formation and no complementarity of government spending, $\theta=0.8$ and $\alpha_{G}=0$ (dotted-dashed lines) and a smaller degree of price rigidity, $\omega_{p}=0.7$ (dashed lines).

In regime $\mathrm{M}$, the real wage falls on impact, despite the initial decline in the wage markup, as the first row of the figure depicts. High estimates of nominal rigidities reduce the real wage's responsiveness to current wage markups, given by $\kappa_{w}$ in equation (4). Instead, expected higher future wage markups drive the real wage down on impact. Higher labor demand raises the marginal rate of substitution, which reduces wage markups initially. But the marginal utility of wealth also rises to more than offset the effect on the marginal rate of substitution over time: gradually wage markups rise and labor declines.

When prices are more flexible (dashed lines), current inflation rises more, depressing the real wage. Firms demand more labor relative to the reference case, given its lower cost, and over time output and consumption increase. Counterfactuals on consumption preferences (dotted-dashed lines) lower consumption demand, muting the responses of labor and the real wage relative to the reference case.

Regime F, which appears in the second row of figure 8, produces much stronger negative wage markups. Positive wealth effects from a higher market value of government debt encourage consumption in regime $\mathrm{F}$, and as more goods are demanded, labor demand expands. Increases in consumption and labor both increase the marginal rate of substitution. Larger, sustained deviations of wage markups from their desired level lead households to raise their nominal wages, causing real wages to rise. Consumption remains positive even without government spending complementarity because in regime $\mathrm{F}$ positive wealth effects from government debt increase consumption and investment demand (dotted-dashed lines). Higher goods and labor demand confirm the importance of positive wealth effects for wage markups in regime F.

Despite these large deviations in markups, it is possible for the real wage to decline on impact in regime $\mathrm{F}$, as the counterfactual with less price stickiness shows (dashed lines). Larger initial $\xi \hat{L}_{t}+\frac{e^{\gamma}}{e^{\gamma}-\theta}\left(\hat{c}_{t}-\frac{\theta}{e^{\gamma}} \hat{c}_{t-1}\right)$.

${ }^{29}$ This result differs from RBC models where real wages decrease with the increase in work effort [see Monacelli and Perotti (2008) for a details]. Several empirical studies, starting with Rotemberg and Woodford (1992), find that an increase in government spending raises real wages and labor [also see Fatas and Mihov (2001), Galí et al. (2007), and Pappa (2009)]. 

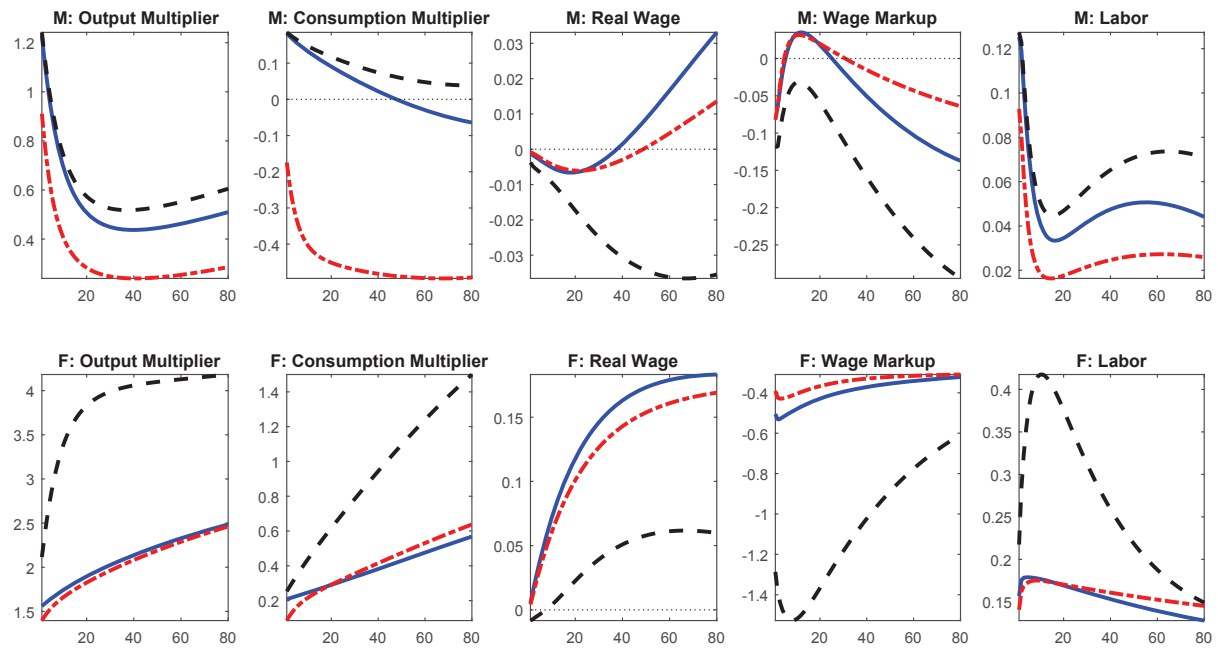

Figure 8: Counterfactual labor market responses to a government spending increase in regime M (top row) and F (bottom row) calibrating both regime using regime F estimates over 1955-2014. Regime M replaces monetary and fiscal parameters with their regime M estimates $\left(\phi_{\pi}=0.90\right.$ and $\left.\gamma_{G}=0.26\right)$. Reference case (solid lines); reduced habits and eliminating complementarity of government spending, $\theta=0.8$ and $\alpha_{G}=0$ (dotted-dashed lines); reduced price rigidities, $\omega_{p}=0.7$ (dashed lines).

increases in prices lower the real wage, but strong negative markups make this effect short-lived. Higher inflation devalues a larger share of government debt, and with more flexible prices, the real interest rates falls; both effects fuel consumption and further depress wage markups, leading the real wage to increase over time.

Returning to our baseline posterior estimates in the two regimes that appear in figure 3, differences in the effects of government spending on real wages lie at the heart of the differences in multiplier estimates. Regime F produces larger declines in wage markups, which lead to higher nominal and real wage adjustments. Coupled with the slightly higher estimated degree of price stickiness in regime $\mathrm{F}$, which further raises real wages on impact, it is not surprising that real wages are far more expansive in regime $\mathrm{F}$.

\subsection{Fiscal Financing in the Two Regimes}

Further insights into the observed differences in multipliers come from accounting for the financing of government spending increases, which differs across policy regimes and sample periods. Letting $\hat{r}_{t}^{B} \equiv\left(\beta \rho / e^{\gamma}\right) \hat{P}_{t}^{B}-\hat{P}_{t-1}^{B}-\hat{\pi}_{t}$ denote the ex-post real return on government bonds and $\hat{S}_{t}$ be the primary surplus, the intertemporal equilibrium condition is ${ }^{30}$

$$
\hat{b}_{t-1}=-\frac{\beta \rho}{e^{\gamma}} \hat{P}_{t}^{B}+\hat{P}_{t-1}^{B}+\hat{\pi}_{t}+(1-\beta) E_{t} \sum_{j=0}^{\infty} \beta^{j} \hat{S}_{t+j}-E_{t} \sum_{j=1}^{\infty} \beta^{j} \hat{r}_{t+j}^{B}
$$

\footnotetext{
${ }^{30}$ The primary surplus consists of the sum of revenues from capital, labor and consumption taxes less lump-sum transfers and government purchases: $\hat{S}_{t}=\frac{T^{K}}{S}\left(\hat{\tau}_{t}^{K}+\hat{r}_{t}^{K}+\hat{K}_{t}\right)+\frac{T^{L}}{S}\left(\hat{\tau}_{t}^{L}+\hat{w}_{t}+\hat{L}_{t}\right)+\frac{T^{C}}{S}\left(\hat{\tau}_{t}^{C}+\hat{C}_{t}\right)-\frac{Z}{S} \hat{Z}_{t}-\frac{G}{S} \hat{G}_{t}$. To focus solely on financing of government purchases, we set all disturbances to zero other than government spending.
} 
The model's rule for government spending at $t$ includes both the exogenous disturbance to spending, $u_{t}^{G}$, and an endogenous response of spending to the debt-output ratio, $\hat{s}_{t-1}^{b}, \hat{G}_{t}=$ $\rho_{G} \hat{G}_{t-1}-\gamma_{G}\left(1-\rho_{G}\right) \hat{s}_{t-1}^{b}+u_{t}^{G}$.

We separate government spending into its exogenous, $\hat{G}_{t}^{x}$, and endogenous, $\hat{G}_{t}^{e}$ components, so $\hat{G}_{t}=\hat{G}_{t}^{x}+\hat{G}_{t}^{e}$. Define the effect on the present value of surpluses of an exogenous change in spending at $t$ by $\xi_{t} \equiv-(1-\beta) \frac{G}{S} E_{t} \sum_{j=0}^{\infty} \beta^{j} \hat{G}_{t+j}^{x}$. We can now split the present value of primary surpluses following a shock to government spending into exogenous and endogenous parts

$$
(1-\beta) E_{t} \sum_{j=0}^{\infty} \beta^{j} \hat{S}_{t+j}=(1-\beta) E_{t} \sum_{j=0}^{\infty} \beta^{j}\left[\hat{S}_{t+j}^{x}+\hat{S}_{t+j}^{e}\right]=\xi_{t}+(1-\beta) E_{t} \sum_{j=0}^{\infty} \beta^{j} \hat{S}_{t+j}^{e}
$$

where $\hat{S}_{t}^{e}$ is the surplus exclusive of exogenous government spending, $\hat{G}_{t}^{x}-\rho_{G} \hat{G}_{t-1}^{x}+u_{t}^{G}$.

Substitute (7) into (6) to yield

$$
\xi_{t}=\hat{b}_{t-1}+\frac{\beta \rho}{e^{\gamma}} \hat{P}_{t}^{B}-\hat{P}_{t-1}^{B}-\hat{\pi}_{t}-u_{t}^{G}+E_{t} \sum_{j=1}^{\infty} \beta^{j} \hat{r}_{t+j}^{B}-(1-\beta) E_{t} \sum_{j=0}^{\infty} \beta^{j} \hat{S}_{t+j}^{e}
$$

Table 12 reports the fraction of $\xi_{t}$ accounted for by each element in (8) dated $t$ and later, with endogenous surpluses broken into their component parts. The table includes posterior means and 90-percent credible sets for the six estimated models, as well as mean predictions for select counterfactuals. Positive entries in the table mean that the component supports financing of higher government spending, while negative entries counter financing.

In both regimes, the baseline estimates (1954-2014) imply that a drop in bond prices at the time of the fiscal shock supports the financing of spending by reducing the market value of debt $\left(\hat{P}_{t}^{B}\right.$ column). Lower $\hat{P}_{t}^{B}$ alone accounts for 11 percent of the financing in regime $\mathrm{M}$ and over 14 percent in F. By spreading inflation into the future, lower bond prices coincide with contemporaneous inflation that accounts for less than 1 percent in each regime $\left(\hat{\pi}_{t}\right.$ column $)$. Because the fiscal expansion raises real interest rates in both $\mathrm{M}$ and $\mathrm{F}$, the higher ex-post return on bonds counters fiscal financing $\left(P V\left(\hat{r}^{B}\right)\right.$ column), and counters more strongly in $\mathrm{M}$, where real rates rise more.

Important financing differences between regimes emerge from the components of the primary surplus. Higher tax revenues - the sum of columns $P V\left(T^{K}\right), P V\left(T^{L}\right)$ and $P V\left(T^{C}\right)$-provide 24 percent of financing in regime $\mathrm{M}$, but nearly 87 percent in $\mathrm{F}$. Under regime $\mathrm{M}$ policies, higher government spending leaves wages unchanged, raises labor moderately, reduces the capital stock, and raises the return to capital to produce offsetting effects that net out to a modest increase in tax revenues. Regime F, in contrast, permits higher spending to raise wages and hours worked dramatically and, if anything, increase the capital stock. This passive, but large, increase in tax revenues in regime $\mathrm{F}$ moderates the wealth effects of fiscal expansions that would otherwise produce huge multipliers. ${ }^{31}$

\footnotetext{
${ }^{31}$ Tables 10 and 11 show that eliminating these passive revenue adjustments by setting steady-state tax rates to zero has little impact on multipliers in regime $\mathrm{M}$, but raises them significantly in regime $\mathrm{F}$.
} 
Of course, if passive tax revenues are not stabilizing debt in regime $\mathrm{M}$, then fiscal adjustments must be occurring on the expenditures side. Posterior estimates of the response of transfers to debt in $\mathrm{M}$ suggest that transfers actually rise with higher debt [see estimate of $\gamma_{Z}$ in table 5]. In the accounting exercise, this policy implies that transfers counter the financing of a fiscal expansion. Financing's heavy lifting comes from endogenous government spending reversals that rise in present value by over 113 percent to compensate for the contrary movement in transfers $[P V(\hat{Z})$ and $P V\left(\hat{G}^{e}\right)$ columns]. This underscores the centrality of government spending reversals in baseline estimates of regime M. Regime F's prior is tightly centered on no response of expenditures to debt, so $P V(Z)$ and $P V\left(G^{e}\right)$ account for less than 0.05 percent of financing.

This general pattern of financing is largely robust across the 1955-1979 and 1982-2007 subperiods. One notable difference is that in the earlier sub-period contemporaneous bond prices play a bigger role in financing in regime $\mathrm{F}$, accounting for nearly a quarter of the expansion in spending. In the earlier sub-period, both transfers and spending help to stabilize debt in regime $\mathrm{M}$, so spending reversals are less pronounced and consumption multipliers are smaller.

The counterfactual exercises whose dynamic impacts appear in figures 5 through 7 shift sources of financing substantially. A Ricardian environment in regime $\mathrm{M}$ reduces the role of debt revaluation through bond prices and current inflation to push nearly all financing into lower future lumpsum transfers. Reduced habits and removing government spending from utility produces stronger spending reversals, with $P V\left(\hat{G}^{e}\right)=130$ percent. More aggressive monetary policy shifts more financing into declines in current bond prices and, by increasing ex-post real returns on debt, raise debt service to produce a higher path for debt that generates still larger spending reversals. In these last two cases, large ultimate declines in government purchases make consumption multipliers higher than they would be in the absence of reversals.

More dramatic reshuffling of fiscal financing appears in regime F counterfactuals. Reduced nominal stickiness enhances the role of debt revaluations to concentrate more than a third of financing in current bond prices and inflation. Because less rigidity reduces real interest rates, ex-post returns on bonds now support the financing of spending. But less expansive real wages and less persistent labor increases conspire to make endogenous tax revenues less important, cutting $P V\left(\hat{S}^{e}\right)$ in half.

Removing the maturity structure on government debt also removes any role for drops in bond prices to support financing. But it also produces larger multipliers and pushes most financing into endogenous tax revenues that account for 100 percent of the present-value increase in government spending. Higher steady-state debt-output makes drops in bond prices and surprise inflation more potent, accounting for 48 percent of financing. The lower associated multipliers reduce the financing role of steady-state tax rates. Of course, the role of endogenous revenues is also diminished when steady-state tax rates are reduced 40 percent. With lower future tax revenues, bond prices and inflation take on larger revaluation roles, as in conventional fiscal theory exercises. 


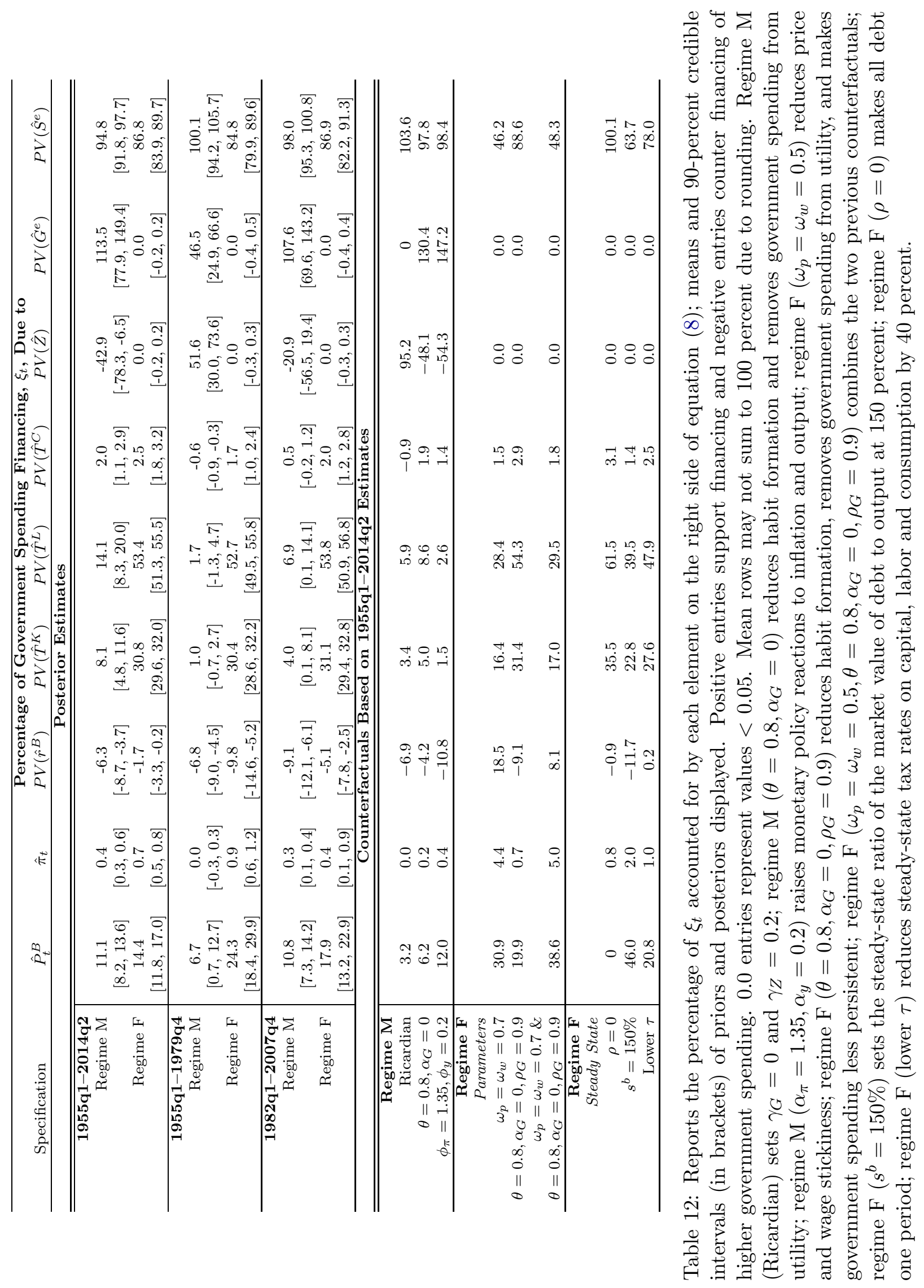




\section{Sequential Estimation}

We briefly address evidence of time variation in the fiscal multiplier. Several studies have argued that multipliers vary over the business cycle [e.g., Auerbach and Gorodnichenko (2012)] and depend upon the time spent at the zero-lower bound [Coenen et al. (2012), Christiano et al. (2011)]. Others have demonstrated that parameter estimates in standard DSGE models tend to exhibit time variation [Fernández-Villaverde and Rubio-Ramírez (2008)]. To assess time variation in multipliers and parameter estimates, we sequentially estimate model 4 of section 2 using a 25-year rolling window with annual steps. That is, we estimate the model using data from 1955:1 through 1979:4, and then repeat the estimation for 1956:1 through 1980:4, 1957:1 through 1981:4, and so on, up to 1989:1 through 2013:4.
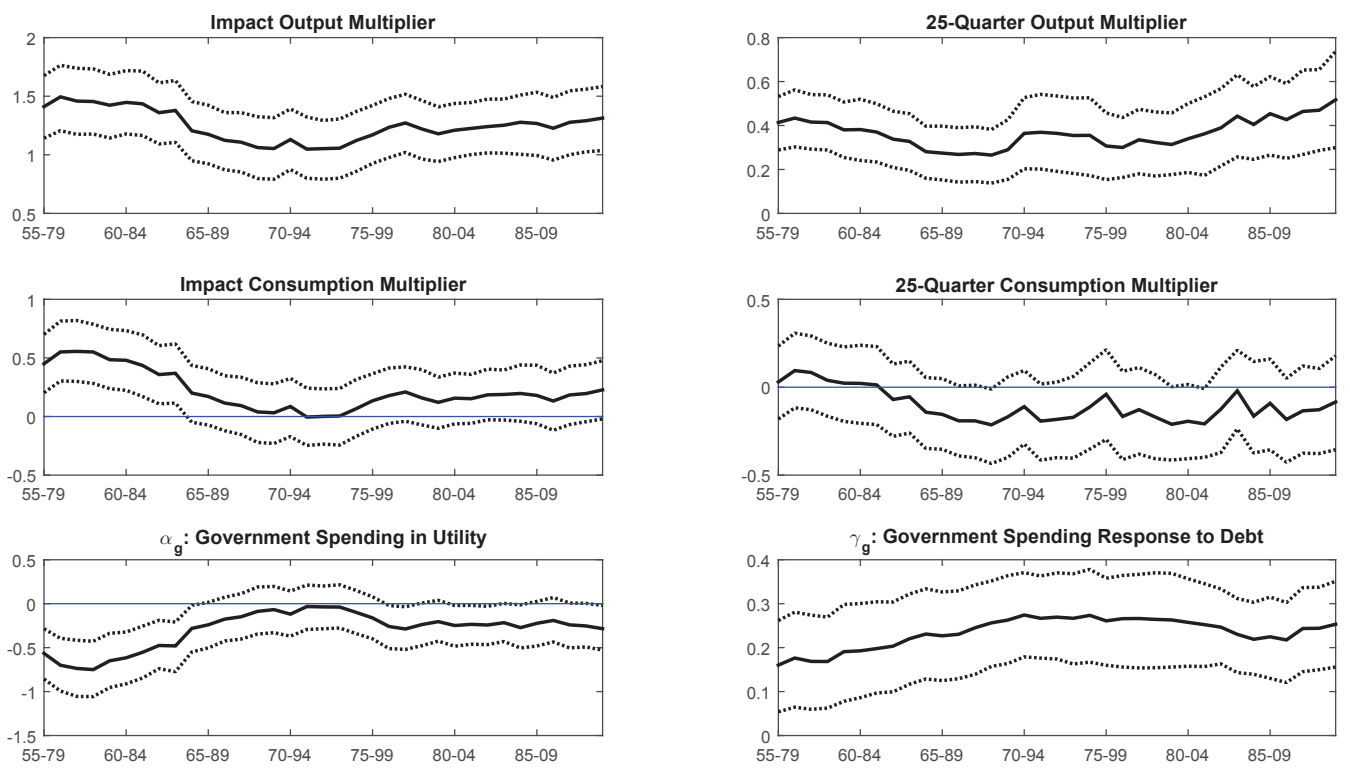

Figure 9: Sequential estimation of the impact multipliers for output and consumption (top row), 25-quarter present value multipliers (middle row), and parameters $\alpha_{G}$ and $\gamma_{G}$ (bottom row) for regime M using data 1955:1 to 1979:4 through 1989:1 to 2013:4. The solid lines are mean values and dashed lines are 90-percent credible sets.

To preserve space, we report only a select few parameters and multipliers. ${ }^{32}$ Figure 9 plots the impact and present-value (25-quarter) multiplier for output (top row) and consumption (middle row) in regime M. Mean values are solid lines, while dashed lines represent 5th and 95th percentiles.

The figure shows modest time variation in the multipliers. Impact consumption and output multipliers follow a similar trend, peaking in the early part of the sample and reaching a minimum around the 1970 to 1994 data set. The mean impact output (consumption) multiplier never dips below one (zero) and reaches a maximum of 1.5 (0.55). As noted above, the estimate of $\alpha_{G}$, which determines the complementarity of government consumption, is a critical parameter for multipliers in regime M. A negative (positive) value of $\alpha_{G}$ implies private and public consumption are com-

\footnotetext{
${ }^{32} \mathrm{~A}$ full set of results are available upon request.
} 
plements (substitutes). Trends in output and consumption impact multipliers mirror movements in $\alpha_{G}$. The early time periods yield a large negative value for $\alpha_{G}$, where impact multipliers are largest. Estimates of $\alpha_{G}$ increase over time, reaching a mean value of zero for the 1971 to 1995 data set. This time period coincides with the smallest impact multipliers.

Longer-horizon multipliers exhibit less variation than the impact multipliers. The mean presentvalue output multiplier begins around 0.4 , dips to roughly 0.3 mid-sample before returning to 0.5 by the end of the sample. The 25-quarter consumption multiplier trends slightly lower for several periods, and then stabilizes around -0.2 beginning with the 1965 to 1989 sample. Movements in the 25-quarter multipliers connect to time variation in $\gamma_{G}$, the strength of spending reversals. This parameter increases over the same horizon that the consumption multiplier is falling, and both stabilize around the same time period. Increases in $\gamma_{G}$ bring forth faster spending reversals. At longer horizons, this makes more goods available to the private sector and increases consumption multipliers. But in the short run, faster spending reversals lower expected government demand, muting inflation responses and raising the real interest rate. The higher real interest rate depresses consumption, explaining the negative relationship between $\gamma_{G}$ and consumption multipliers at the 25-quarter horizon.

Figure 9 underscores the tightness of the estimates for the multipliers and parameters for all time periods. Recall that the prior predictive range for impact multipliers extends well beyond two (one) and below zero (-0.5) for output (consumption). The 90-percent posterior credible sets are much narrower than the prior predictive analysis, indicating that the data are informative.

\section{Concluding Remarks}

This paper differs from the bulk of research on government spending multipliers in several ways: (1) expands the set of observables used in estimation; (2) fills out details on the fiscal side of the model, including explicit rules for fiscal instruments, maturity structure of government debt, government spending that may complement or substitute for private consumption, distorting steady-state taxes; (3) adopts more diffuse priors over nominal rigidities and habit formation; (4) permits the posterior to land in regions of the parameter space that uncover fresh perspectives on the transmission mechanism of government spending; (6) finds that monetary-fiscal regime is important for the size and persistence of multipliers: they are larger and more persistent in regime $\mathrm{F}$, but even regime $\mathrm{M}$ estimates produce larger and longer lasting multipliers than most studies.

Our model departs from many others by permitting government spending to enter utility and allowing data to determine whether public goods substitute for or complement private consumption. This is a crude way to deviate from the common assumption that government spending is "unproductive" or "wasteful." More detailed analysis would divide spending into its uses - pure public goods, national defense, wages of government employees, infrastructure, and so forth-and aim to model each component. Surely government spending's impacts hinge on its uses.

The paper highlights an issue that transcends multipliers: getting the prevailing monetaryfiscal policy regime right is the first order of business for understanding macroeconomic policy 
impacts. Fiscal details that bring the model closer to actual policy environments matter a great deal for making regime $\mathrm{F}$ dynamics palatable to data. These details, together with other aspects of model specifications - private sector behavior, the role of government spending, policy rulesrequire systematic study to understand their contributions to model fit. 


\section{REFERENCES}

Aiyagari, S. R., L. J. Christiano, and M. Eichenbaum (1992): "The Output, Employment, and Interest Rate Effects of Government Consumption," Journal of Monetary Economics, 30, $73-86$.

Aschauer, D. A. (1985): "Fiscal Policy and Aggregate Demand," American Economic review, 75.

Auerbach, A. J. And Y. Gorodnichenko (2012): "Measuring the Output Responses to Fiscal Policy," American Economic Journal: Economic Policy, 4, 1-27.

Barro, R. J. (1981): "Output Effects of Government Purchases," Journal of Political Economy, $89,1086-1121$.

Baxter, M. And R. G. King (1993): "Fiscal Policy in General Equilibrium," American Economic Review, 86, 1154-1174.

Bilbiıe, F. (2009): "Non-Separable Preferences, Fiscal Policy Puzzles and Inferior Goods," Journal of Money, Credit and Banking, 41, 443-450.

(2011): "Nonseparable Preferences, Frisch Labor Supply, and the Consumption Multiplier of Government Spending: One Solution to a Fiscal Policy Puzzle," Journal of Money, Credit and Banking, 43, 221-251.

Bouakez, H. And N. Rebei (2007): "Why Does Private Consumption Rise After a Government Spending Shock?" Canadian Journal of Economics, 40, 954-979.

Calvo, G. A. (1983): "Staggered Prices in a Utility Maxmimizing Model," Journal of Monetary Economics, 12, 383-398.

Christiano, L., M. Eichenbaum, and S. Rebelo (2011): "When Is the Government Spending Multiplier Large?" Journal of Political Economy, 119, 78-121.

Christiano, L. J. And M. Eichenbaum (1992): "Current Real-Business-Cycle Theories and Aggregate Labor-Market Fluctuations," American Economic Review, 82, 430-450.

Christiano, L. J., M. Eichenbaum, and C. L. Evans (2005): "Nominal Rigidities and the Dynamic Effects of a Shock to Monetary Policy," Journal of Political Economy, 113, 1-45.

Chung, H. And E. M. Leeper (2007): "What Has Financed Government Debt?" National Bureau of Economic Research Working Paper No. 13425.

Cochrane, J. H. (1999): "A Frictionless View of U.S. Inflation," in NBER Macroeconomics Annual 1998, ed. by B. S. Bernanke and J. J. Rotemberg, Cambridge, MA: MIT Press, vol. 14, 323-384. 
- (2001): "Long Term Debt and Optimal Policy in the Fiscal Theory of the Price Level," Econometrica, 69, 69-116.

Coenen, G., C. Erceg, C. Freedman, D. Furceri, M. Kumhof, R. Lalonde, D. Laxton, J. Lindé, A. Mourougane, D. Muir, S. Mursula, C. De Resende, J. Roberts, W. Roeger, S. Snudden, M. Trabandt, and J. in't Veld (2012): "Effects of Fiscal Stimulus in Structural Models," American Economic Journal: Macroeconomics, 22-68.

Coenen, G. And R. Straub (2005): "Does Government Spending Crowd In Private Consumption? Theory and Empirical Evidence for the Euro Area," International Finance, 8, 437-470.

Cogan, J. F., T. Cwik, J. B. Taylor, and V. Wieland (2010): "New Keynesian versus Old Keynesian Government Spending Multipliers," Journal of Economic Dynamics and Control, 34, 281-295.

Colciago, A. (2011): "Rule-of-Thumb Consumers Meet Sticky Wages," Journal of Money, Credit and Banking, 43, 325-353.

Corsetti, G., A. Meier, And G. Müller (2012): "Fiscal Stimulus with Spending Reversals," The Review of Economics and Statistics, 94, 878-895.

Davig, T. And E. M. Leeper (2011): "Monetary-Fiscal Policy Interactions and Fiscal Stimulus," European Economic Review, 55, 211-227.

Del Negro, M. and F. Schorfheide (2008): "Forming Priors for DSGE Models (and How It Affects the Assessment of Nominal Rigidities)," Journal of Monetary Economics, 55, 1191-1208.

Devereux, M. B., A. C. Head, And B. J. Lapham (1996): "Monopolistic Competition, Increasing Returns, and the Effects of Government Spending," Journal of Money, Credit and Banking, $28,233-254$.

Drautzburg, T. And H. Uhlig (2013): "Fiscal Stimulus and Distortionary Taxes," Federal Reserve Bank of Philadelphia, working paper.

Dupor, B. And R. Li (2015): "The Expected Inflation Channel of Government Spending in the Postwar U.S." European Economic Review, 74, 36-56.

Erceg, C. J., L. Guerrieri, and C. J. Gust (2006): "SiGMA: A New Open Economy Model for Policy Analysis," International Journal of Central Banking, 2.

Fatas, A. And I. Minov (2001): "The Effects of Fiscal Policy on Consumption and Employment: Theory and Evidence," Mimeo, INSEAD.

Faust, J. And A. Gupta (2010): "Posterior Predictive Analysis for Evaluating DSGE Models," Working Paper, Johns Hopkins University. 
Fernández-Villaverde, J. and J. F. Rubio-Ramírez (2008): "How Structural Are Structural Parameters?" in NBER Macroeconomics Annual 200\%, ed. by D. Acemoglu, K. Rogoff, and M. Woodford, Chicago, IL: University of Chicago Press, vol. 22.

Fève, P., J. Matheron, And J.-G. Sahuc (2011): "Externality in Labor Supply and Government Spending," Economic Letters, 112, 273-276.

— (2013): "A Pitfall with Estimated DSGE-Based Government Spending Multipliers," American Economic Journal: Macroeconomics, 5, 141-178.

Finn, M. G. (1998): "Cyclical Effects of Government's Employment and Goods Purchases," International Economic Review, 39, 635-657.

Forni, L., L. Monteforte, And L. Sessa (2009): "The General Equilibrium Effects of Fiscal Policy: Estimates for the Euro Area," Journal of Public Economics, 93, 559-585.

Furlanetto, F. (2011): "Fiscal Stimulus and the Role of Wage Rigidity," Journal of Economic Dynamics and Control, 35, 512-527.

Galí, J., J. D. López-Salido, And J. VAllÉs (2007): "Understanding the Effects of Government Spending on Consumption," Journal of the European Economic Association, 5, 227-270.

Gechert, S. And H. Will (2012): "Fiscal Multipliers: A Meta Regression Analysis," IMK Working Paper No. 97, July.

Geweke, J. (1999): "Using Simulation Methods for Bayesian Econometric Models: Inference, Development, and Communication," Econometric Reviews, 18, 1-73.

- (2010): Complete and Incomplete Econometric Models, Princeton, NJ: Princeton University Press.

Havranek, T., M. Rusnak, And A. Sokolova (2015): "Habit Formation in Consumption: A Meta-Analysis," Czech National Bank Working Paper No. 2015/03.

Herbst, E. And F. Schorfheide (2014): "Sequential Monte Carlo Sampling for DSGE Models," Journal of Applied Econometrics, 29, 1073-1098.

Jones, J. B. (2002): "Has Fiscal Policy Helped Stabilize the Postwar U.S. Economy?" Journal of Monetary Economics, 49, 709-746.

KIm, S. (2003): "Structural Shocks and the Fiscal Theory of the Price Level in the Sticky Price Model," Macroeconomic Dynamics, 7, 759-782.

Leeper, E. M. (1991): "Equilibria Under 'Active' and 'Passive' Monetary and Fiscal Policies," Journal of Monetary Economics, 27, 129-147. 
Leeper, E. M. And C. Leith (2017): "Inflation Through the Lens of the Fiscal Theory," in forthcoming in Handbook of Macroeconomics, ed. by J. B. Taylor and H. Uhlig, Amsterdam: Elsevier Press, vol. 2.

Leeper, E. M., M. Plante, and N. Traum (2010): "Dynamics of Fiscal Financing in the United States," Journal of Econometrics, 156, 304-321.

Leeper, E. M., N. Traum, and T. B. Walker (2011): "Clearing Up the Fiscal Multiplier Morass," NBER Working Paper No. 17444, September.

Linnemann, L. And A. Schabert (2004): "Can Fiscal Spending Stimulate Private Consumption?" Economic Letters, 82, 173-179.

Lopez-Salido, J. D. And P. Rabanal (2006): "Government Spending and Consumption-Hours Preferences," La Caixa Working Paper Series No. 02/2006, November.

McGrattan, E. R. (1994): "The Macroeconomic Effects of Distortionary Taxation," Journal of Monetary Economics, 33, 573-601.

Mendoza, E. G., A. Razin, and L. L. Tesar (1994): "Effective Tax Rates in Macroeconomics Cross-country Estimates of Tax Rates on Factor Incomes and Consumption," Journal of Monetary Economics, 34, 297-323.

Monacelli, T. And R. Perotti (2008): "Fiscal Policy, Wealth Effects, and Markups," National Bureau of Economic Research Working Paper No. 14584, December.

PAPPA, E. (2009): "The Effects of Fiscal Shocks on Employment and the Real Wage," International Economic Review, 50, 217-244.

Ramey, V. A. (2011): "Can Government Purchases Stimulate the Economy?" Journal of Economic Literature, 49, 673-685.

Ravn, M., S. Schmitt-Grohé, And M. Uribe (2006): "Deep Habits," Review of Economic Studies, 73, 195-218.

Rotemberg, J. J. And M. Woodford (1992): "Oligopolistic Pricing and the Effects of Aggregate Demand on Economic Activity," Journal of Political Economy, 100, 1153-1207.

Sims, C. A. (1994): "A Simple Model for Study of the Determination of the Price Level and the Interaction of Monetary and Fiscal Policy," Economic Theory, 4, 381-399.

(2013): "Paper Money," American Economic Review, 103, 563-84.

Smets, F. And R. Wouters (2003): "An Estimated Dynamic Stochastic General Equilibrium Model of the Euro Area," Journal of the European Economic Association, 1, 1123-1175. 
(2005): "Comparing Shocks and Frictions in U.S. and Euro Business Cycles: A Bayesian DSGE Approach," Journal of Applied Econometrics, 20, 161-183.

- (2007): "Shocks and Frictions in US Business Cycles: A Bayesian DSGE Approach," American Economic Review, 97, 586-606.

TAN, F. (2014): "Two Econometric Interpretations of U.S. Fiscal and Monetary Policy Interactions," Indiana University manuscript.

Traum, N. And S.-C. S. Yang (2011): "Monetary and Fiscal Policy Interactions in the Post-War U.S." European Economic Review, 55, 140-164.

- (2015): "When Does Government Debt Crowd Out Investment?" Journal of Applied Econometrics, 30, 24-45.

Uhlig, H. (2010): "Some Fiscal Calculus," American Economic Review: Papers 8 Proceedings, $100,30-34$.

Woodford, M. (1995): "Price-Level Determinacy Without Control of a Monetary Aggregate," Carneige-Rochester Conference Series on Public Policy, 43, 1-46.

- (2011): "Simple Analytics of the Government Expenditure Multiplier," American Economic Journal: Macroeconomics, 3, 1-35.

Zubairy, S. (2014): "On Fiscal Multipliers: Estimates from a Medium-Scale DSGE Model," International Economic Review, 55, 169-195. 